تحليل أهمية الموضوعات البحثية الإرشادية بواسطة الباحثين الإششاديين بمعهد بحوث الإرشاد الزراعي والتنمية الريفية

مجدي عبد الوهاب خطاب '، مصطفى كمال حافظ'، الصاوي أنور الصاوي'، أسماء محمد عوض الله'

$$
\text { و شريف رشاد شعبان' }
$$

الاستبيان بالمقابلة الثخصية في شهري يوليو وأغسطس 1 ا.ب، ونظراً لطبيعة أهداف هذه الدراسة فقد تم استخدام

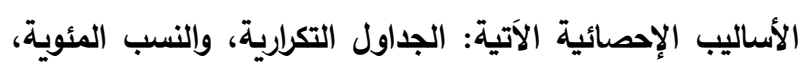

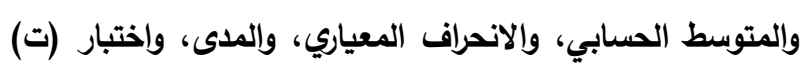

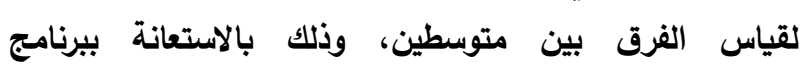

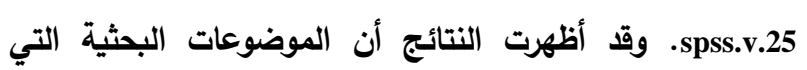

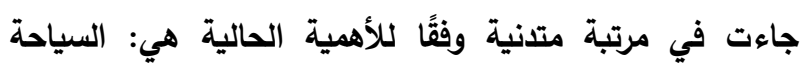
الريفية، وإمكانية تقديم خدمة الإرشادية مدفوعة الأجر، ودية الإدور وسائط التعليم عن بعد في العمل الإرشادي، ومستوى ألداء

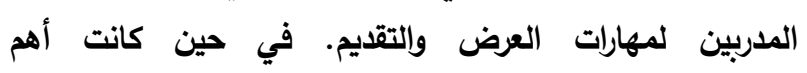

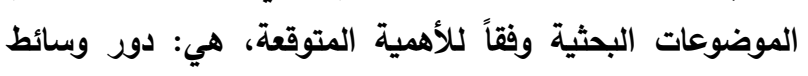

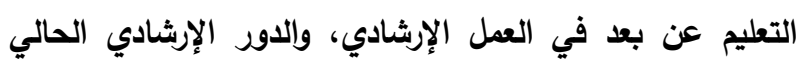

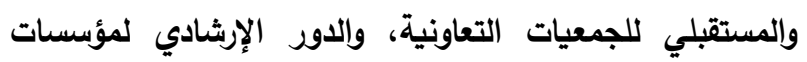

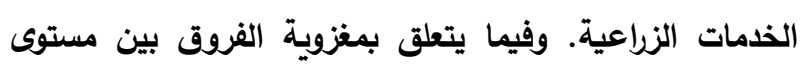

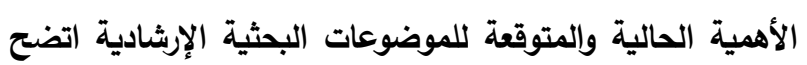

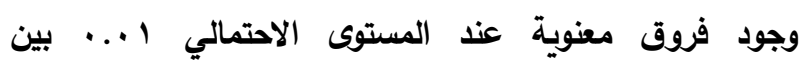

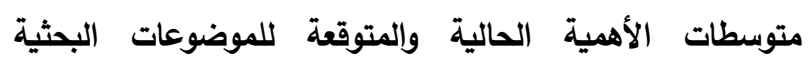

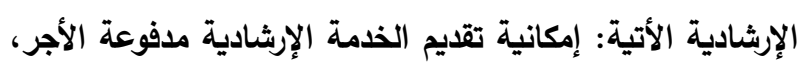

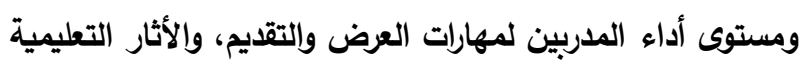

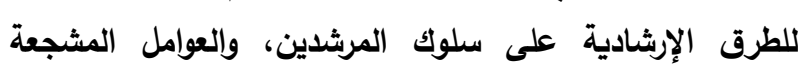
للمشاركة بالأنثطة الإرشادية الزراعية. وعند المستوى الاحتمالي الإني

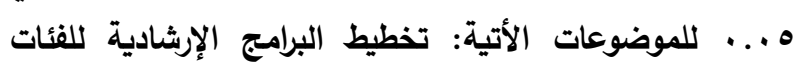

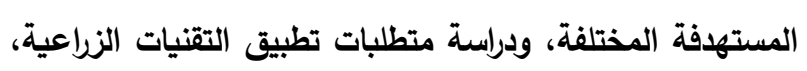
وتقييم البرامج التدريبية المنفذة لتنمية قدرات الموارد البشرية، والزراعة التعاقدية، وتحسين وتطوير الجهاز التنظيمي الإرشادي لتبني

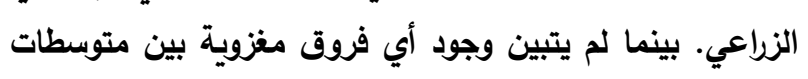

$$
\text { الملخص العربى }
$$

استهافت هذه الاراسة بصفة رئيسية تحليل أهمية الموضوعات البحثية الإرشادية بواسطة الباحثين الإرشاديين

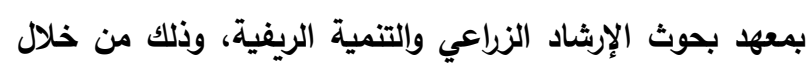

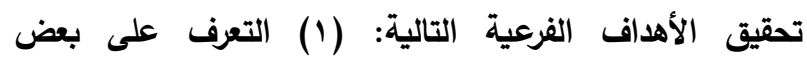

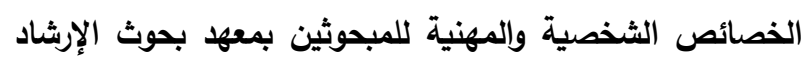

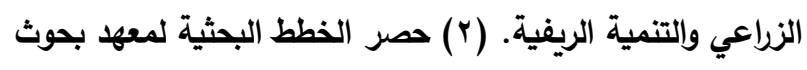

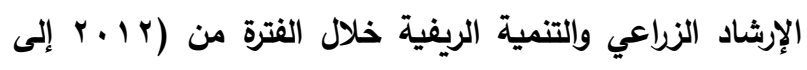

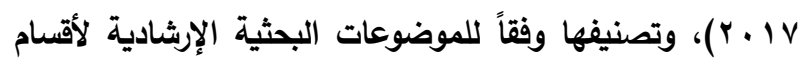

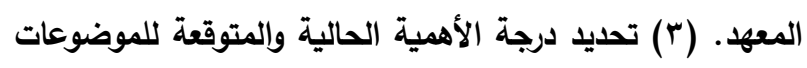

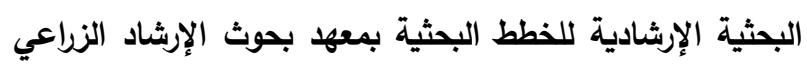

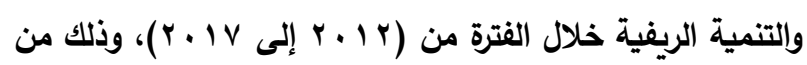

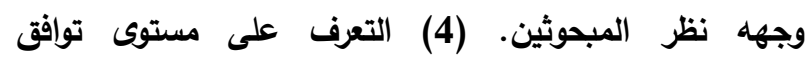
الموضوعات البحثية الإرشادية لخطط معه بحوث الإنهان

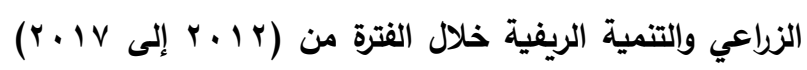

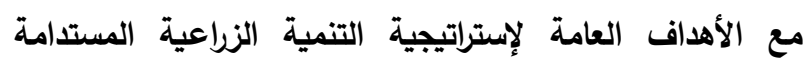

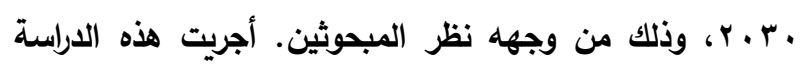

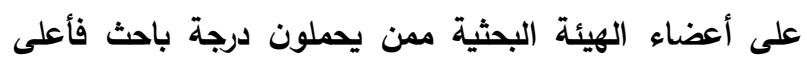

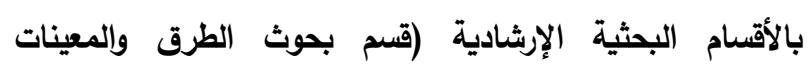

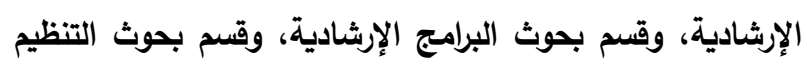

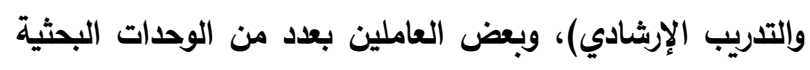

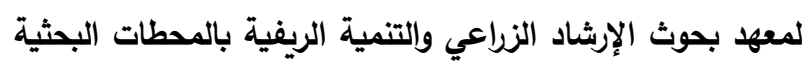

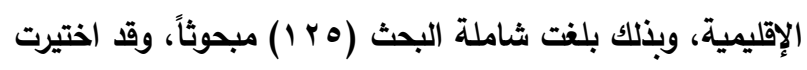

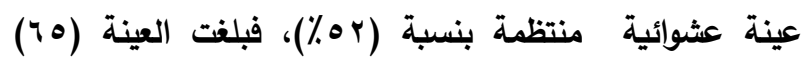
مبحوثاً، وقد تم تجميع البيانات البثثية منهم جميعاً من خلال

$$
\begin{aligned}
& \text { 'قتم الإرشاد الزراعي - كلية الززراعة- جامعة الإنكندرية }
\end{aligned}
$$

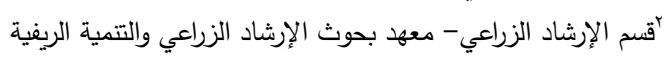

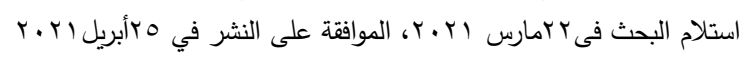


النامية إلى استخدام وتطبيق الدكتثفات العلمية والوسائل

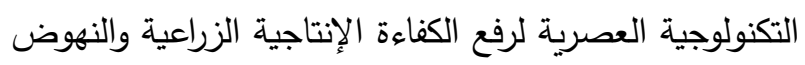
بمعدلات الإنتاج الزراعي التي تعتبر من أبرز الوسائل

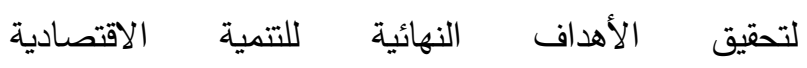
والاجتماعية (Alston, 2010, P. 7). ويمكن القول بصفه عامه أن البحوث الزراعية وليدة

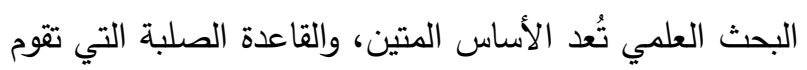
عليها النهضة الزراعية في أي دولة عصرية (الطنوبي،

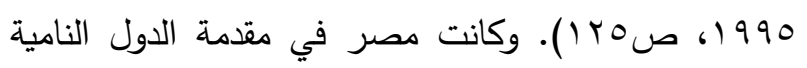

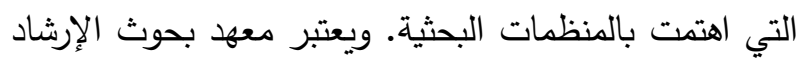

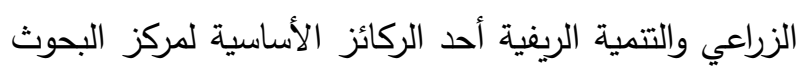

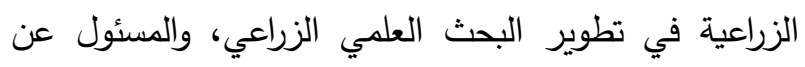

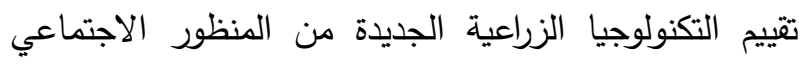

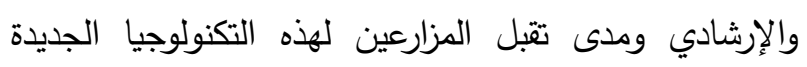

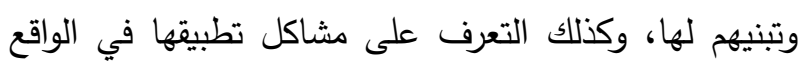
الميداني من خلال تطوير الخدمة الإرشادية الزراعية بما يوائم

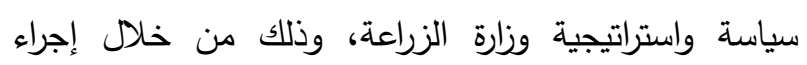

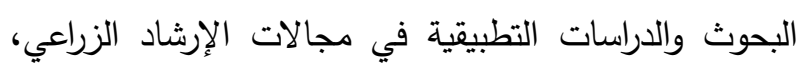

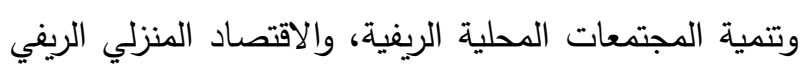

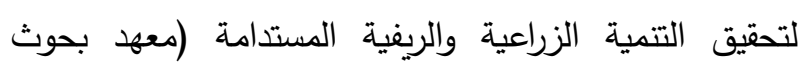

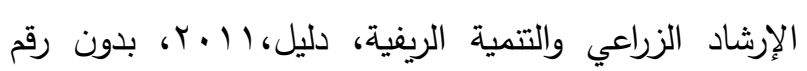

صفحة).

وعند اختيار موضوعات البحوث الزراعية وأولوياتها وآلية اختيارها، فإن الأسئلة الأساسية التي تتبادر إلى الذهن هنات النها:

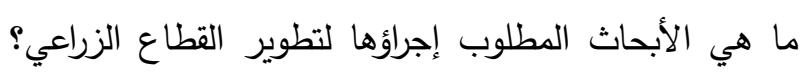

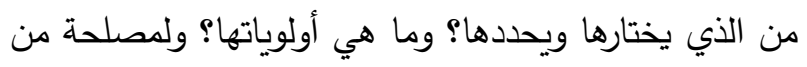

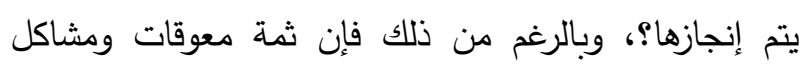

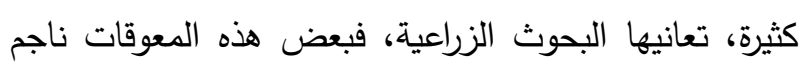

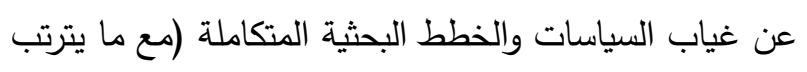

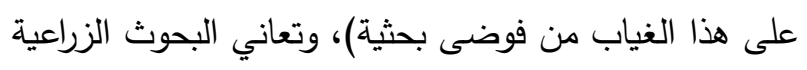

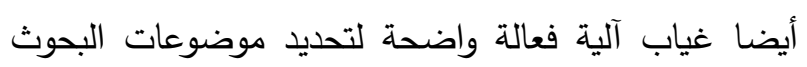

لأهمية الحالية والأهمية المتوقعة لكل من الموضوعات البحثية

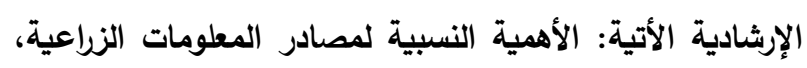

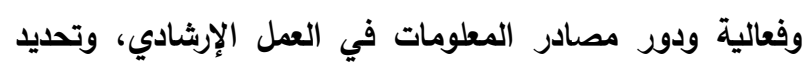

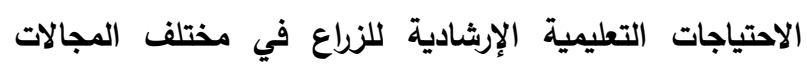

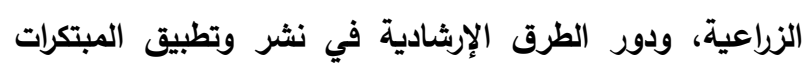

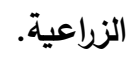
وتثير النتائج أن قرابة ثلاثة أرباع المبحوثين

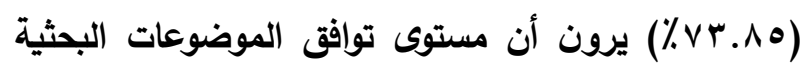

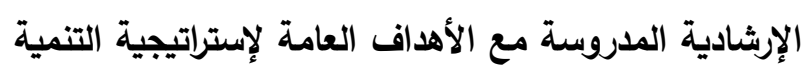

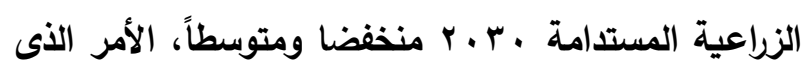

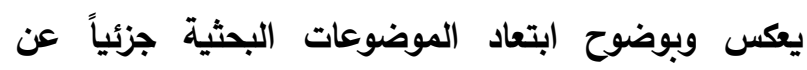
تحقيق الأهداف العامة لإستراتيجية التنمية الزبراعية البعادية

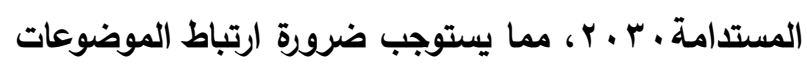

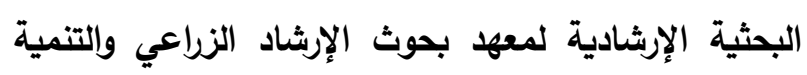
الريفية بالأهداف العامة للإستراتيجية المذكورة من جهة، الإنية وتثديد الإثراف من المسئولين عن تنفيذ الخطط البحثية للمعهة ليأتي العمل البحثي متوافقاً مع استراتيجية التنمية

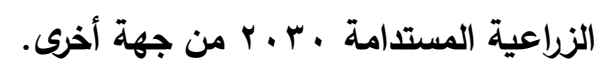

الكلمات المفتاحية: الموضوعات البحثية الإرشادية،

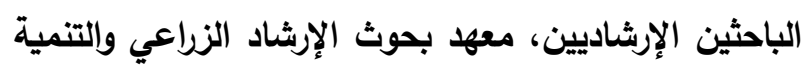
الريفية

\section{المقدمة والمشكلة البحثية}

في ظل تصاعد التتافسية والاحتكار بين الدول المتقدمة تزداد حاجة الدول النامية ومن بينها مصر إلى إيجاد بيئة

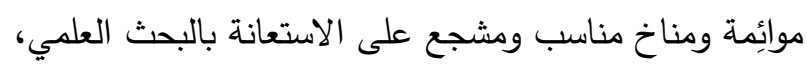
والذي يُعتبر قاطرة التمية في المجتمعات خاصة النئية النامية

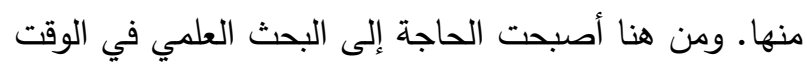

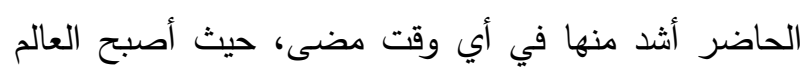
في سباق للوصول إلى أكبر قدر ممكن من المعرفة الدقيقة

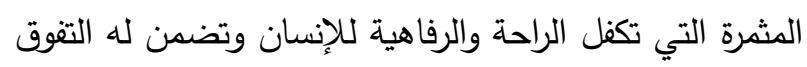

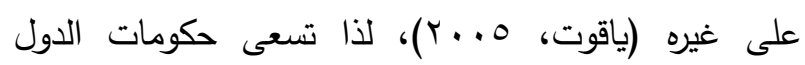


اللازمة بصورة دورية، وتصنيفها وفق أولويات محددة، التعاريف الإجرائية

مفهوم البحث العلمي: هو أسلوب منظم في جمع المعلومات

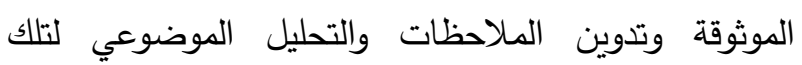
المعلومات باتباع أساليب ومناهج علمية محددة بقصد التأكد وفئ من صحتها أو تعديلها أو إضافة الجديد لها، ومن ثم التوصل إلى بعض القوانين والنظريات والتتبؤ بحدوث مثل هذه

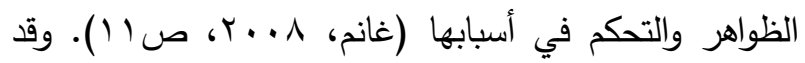
تعددت التعاريف التي وضعت لمفهوم البحث العلمي، وحاول العلماء والباحثين تتاول أبعاد مختلفة لتعريفه أو وصفه ومنها على سبيل التمثيل لا الحصر تعريف كل من محمد (9V9)

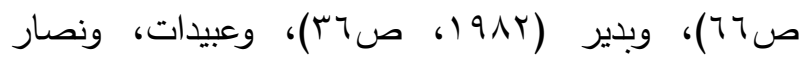

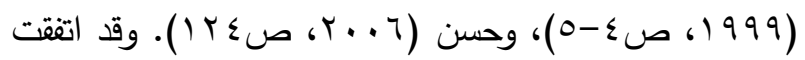
هذه التعريفات على الأبعاد التالية: (1) البحث العلمي

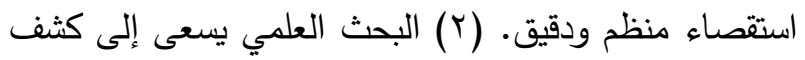

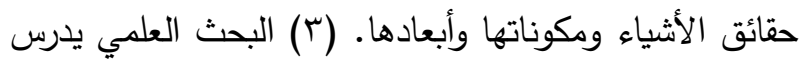

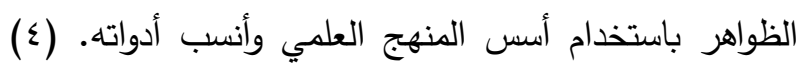
البحث العلمي يساعد في حل المشكلات. (0) البحث العلمي يستخلص المبادئ العامة والقوانين التقسيرية. أهمية البحث العلمي: يعتبر البحث العلمي أهم مؤشرات التقدم في أي مجتمع، فهو يستهدف توليد وإنتاج المعرفة والتكنولوجيا الحديثة التي تساعد على إثباع الاحتياجات البشرية الأساسية من خلال فهم الظواهر المختلفة المحيطة بالإنسان كالظواهر الطبيعية والاجتماعية، والتنبؤ بها، والتحكم فيها لتحسين نوعية الحياة، والبحث العلمي هو أفضل طريقة موضوعية للحصول على المعرفة المنظمة في المجالات المختلفة، والتي تراكمت في كل مجال لتصنع علماً قائماً بذاته. وقد أصبح معدل توليد واستخدام المعرفة والتكنولوجيا الحديثة أحد أهم مؤشرات التقدم في أي مجتمع. لذا تحاول الدول المختلفة استخدام البحث العلمي في كافة المجالات لتطوير اقتصادياتها (الثافعي، . • ب، ص999).
ومتابعة تنفيذها وتقييمها وفق معايير علمية ووطنية واضحة وصارمة وعدم الاستفادة من نتائج البحوث وعدم توظيفها في

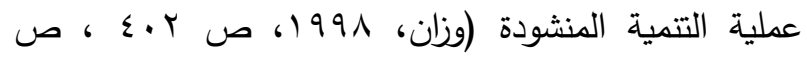
$\cdot(\varepsilon \cdot r$ وانطلاقاً مما سبق، تسعى هذه الدراسة إلى تحليل أهمية الموضوعات البحثية الإرشادية بواسطة الباحثين الإرشاديين بمعه بحوث الإرشاد الزراعي والتتمية الريفية كخطوه على الطريق نحو توجيه البحوث المستقبلية في مجال العمل بلإل الإرشادي الزراعي والتتمية الريفية.

\section{الاهداف البحثية}

تستهدف هذه الدراسة بصفة رئيسية تحليل أهمية الموضوعات البحثية الإرشادية بواسطة الباحثين الإرشاديين بمعهد بحوث الإرشاد الزراعي والتتمية الريفية وذلك من خلال تحقيق الأهداف الفرعية التالية: ا ـ التعرف على بعض الخصائص الثخصية والمهنية للمبحوثين بمعهد بحوث الإرشاد الزراعي والتتمية الريفية. r. حصر الخطط البحثية لمعهد بحوث الإرشاد الزراعي

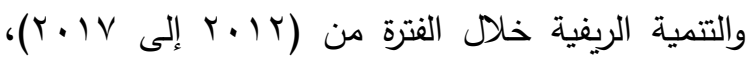
وتصنيفها وفقاً للموضوعات البحثية الإرشادية لأقسام المعهد. r. تحديد مستوى الأهمية الحالية والمتوقعة للموضوعات البحثية الإرشادية للخطط البحثية بمعهد بحوث الإرشاد

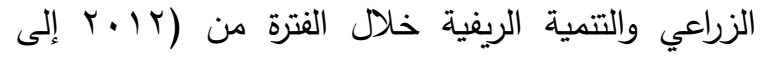

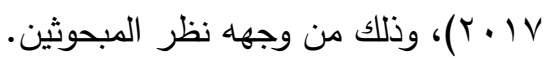
ع. التعرف على مستوى توافق الموضوعات البحثية الإرشادية لخطط معهد بحوث الإرشاد الزراعي والتتمية الريفية خلال

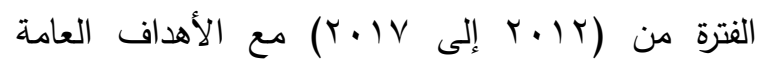

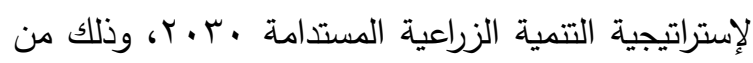

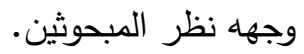


وعدد البحوث المنشورة، ومستوى التدريب المهني، ومستوى الرضا الوظيفي، ومستوى تأثير الهيئات والمنظمات ذات الصلة بالعمل البحثي. ومن الجدير بالأكر أن مستوى التدريب المهني: يُشار إليه في هذه الدراسة بعدد الدورات

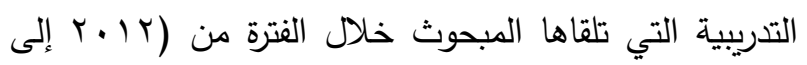

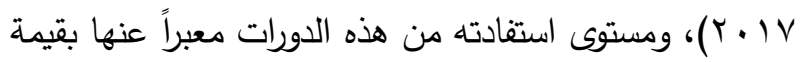
رقمية حيث أعطى المبحوث درجتان في حاله الحضور لكل دورة خارج مصر ودرجة واحدة في حاله حضورها داخل

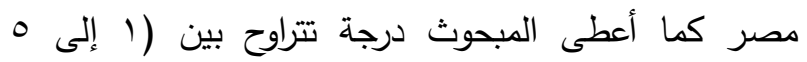
درجات) على الترتيب للتعبير عن مدى الاستفادة من كل دورة

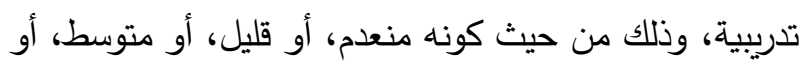

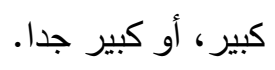

مستوى الرضا الوظيفي: يُشار إليه في هذه الدراسة بالقيمة الرقمية المعبرة عن استجابة المبحوث على سته مؤشرات تدور حول المهام الوظيفية، وعلاقات العمل، ونظم التحفيز، ومعبراً عنها بقيم رقمية تتراوح بين (1 إلى ب درجات) على الترتيب حيث أعطي المبحوث ثلاث درجات في حالة الرضا التام، ودرجتان في حالة الرضا لحد ما، ودرجة في حالة عدم الرضا.

مستوى تأثير الهيئات والمنظمات ذات الصلة بالعمل البحثي: يقصد بها في هذا البحث آراء المبحوثين في تأثير

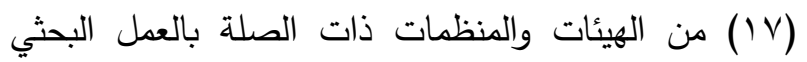
على أداء دورهم البحثي، وذلك من حيث كونها لا تؤثر ، أو ذات تأثير منخفض، أوتؤثر إلى حد ما، أوذات تأثير مرتفع،

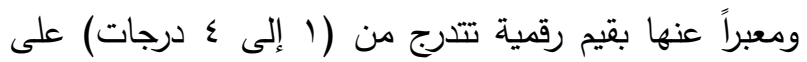
الترتيب.

مستوى الأهمية الحالية للموضوعات البحثية الإرشادية: يقصد بها في هذه الدراسة تقدير المبحوثين الذاتي لأهمية الموضوعات البحثية في الوقت الراهن المرتبطة والمدرجة بالخطط البحثية لمعهد بحوث الإرشاد الزراعي والتتمية الريفية

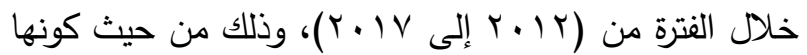

معهد بحوث الإرشاد الزراعي والتنمية الريفية: يعتبر معهد بحوث الإرشاد الزراعي والتتمية الريفية أحد المعاهد البحثية التابعة لمركز البحوث الزراعية بوزارة الزراعة واستصلاح الأراضي بجمهورية مصر العربية، والذى أنثئ في يناير عام I9VV تحديد المعوقات التي تواجه المنتجين الزراعيين في إنتاج المحاصيل الحقلية، والمحاصيل البستانية، والإنتاج الحيواني، وكذلك تحديد طرق التعليم الإششادي المناسبة لتوصيل التقنيات الزراعية إلى المزارعين، وتقديم الحلول العلمية المناسبة للتغلب على المشكلات الاجتماعية في المجتمعات المحلية الريفية، وتحديد احتياجات المرأة الريفية في الزراعة والاقتصاد المنزلي الريفي (معهد بحوث الإرشاد الزراعي

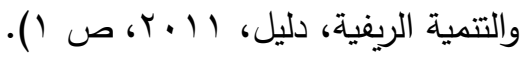

الأهداف العامة لإستراتيجية التنمية الزراعية المستدامة • • r. هي: (1) الاستخدام المستدام للموارد الزراعية

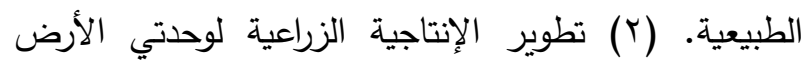
والمياه. (r) تحقيق درجة أعلى للأمن الغذائي من سلع الغذاء الإستراتيجية. (ع) تدعيم القدرة التتافسية للمنتجات الزراعية في الأسواق المحلية والدولية. (0) تحسين مناخ الاستثمار الزراعي. (7) تحسين مستوى معيشة السكان الريفيين وتخفيض معدلات الفقر الريفي. وزارة الزراعة واستصلاح

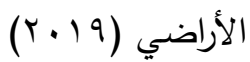
المبحوثين: يقصد بهم مجموع الباحثين العاملين بالأقسام الإرشادية التالية: (قسم بحوث الطرق والمعينات، وقسم بحوث البرامج الإرشادية، وقسم بحوث التدريب والتظيلم) بمعهد بحوث الإرشاد الزراعي والتتمية الريفية فقط، ويشغلون الدرجات الوظيفية التالية: (باحث، وباحث أول، ورئيس بحوث، ورئيس بحوث متفرغ).

الخصائص الثخصية والمهنية المدروسة: يقصد بها مجموعة الخصائص التي تتحصر في: السن، والتخصص الوظيفي، والدرجة الوظيفية البحثية، والخبرة الوظيفية البحثية، 


\section{شاملة وعينة البحث}

اقتصر هذا البحث على مجموع الهيئة البحثية للأقسام البحثية الإرشادية الثلاثة بمعهد بحوث الإرشاد الزراعي والتمية الريفية (قسم بحوث الطرق والمعينات الإرشادية، وقسم بحوث البرامج الإرشادية، وقسم بحوث التنظيم والتدريب الإرشادي) والعاملين بكل من (1) المقر الرئيسي للمعهد بمحافظة الجيزة.(r) محطه بحوث شمال الالتا.(r) محطه بحوث وسط الالتا.(ع) محطه بحوث الإسكندرية.(0) محطه بحوث الأراضي الجديدة بالنوبارية، وبذلك بلغت الثاملة وفقا

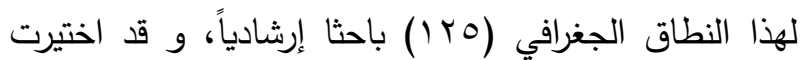
عينة عشوائية بنسبة (Y\%\%)، وبلغت عينة البحث (0) باحثاً إرشادياً تم تجميع البيانات منهم جميعاً. مصادر بيانات البحث اعتمد هذا البحث على مصادر أولية تمثلت في: المبحوثين المختارون بالوحدات البحثية المختارة لمعهد بحوث الإرشاد الزراعي والتتمية الريفية للإجابة على التساؤلات البحثية الواردة باستمارة البحث. ومصادر ثانوية تمثلث في: الدراسات والأبحاث والتقارير والمطبوعات والإحصائيات المختلفة التي استخدمت بياناتها للوقوف على طبيعة العمل البحثي بمقار عملهم بما يفيد في تصميم استمارة البحث في مختلف مراحل تخطيط وتنفيذ الدراسة.

أساليب تجميع البيانات البحثية تم الاعتماد على الاستبيان بالمقابلة الثخصية كأداة لتجميع البيانات. وقد تم إجراء اختبار مبدئي Pre - Test لاستمارة البحث على عدد من المبحوثين من خارج العينة تم اختيارهم عشوائياً، وذلك بهدف التعرف على مدى ملاءمتها ووضوح محتوياتها، وفى ضوء نتيجة هذا الاختبار تم صياغة الاستمارة في صورتها النهائية. وتم تجميع البيانات خلال

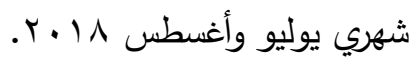

غير هامة، أو قليلة الأهمية، أو متوسطة الأهمية، أو هامة،

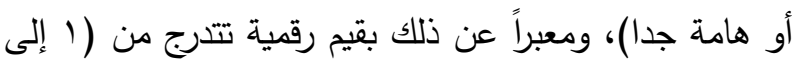
ه درجات) على الترتيب. مستوى الأهمية المتوقعة للموضوعات البحثية الإرشادية: يقصد بها في هذه الدراسة تقدير المبحوثين الذاتي للأهمية المستقبلية للموضوعات البحثية المرتبطة والمدرجة بالخطط البحثية لمعهد بحوث الإرشاد الزراعي والتتمية الريفية خلال

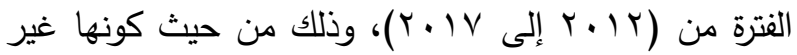
هامة، أو قليلة الأهمية، أو متوسطة الأهمية، أو هامة، أو

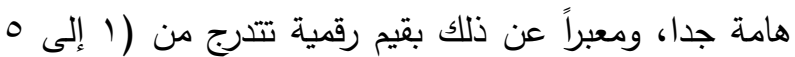
درجات) على الترتيب.

\section{مستوى توافق الموضوعات البحثية الإرشادية ميع} الأهداف العامة لإستراتيجية التتمية الزراعية المستدامة

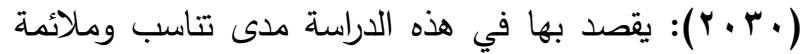
الموضوعات البحثية الإششادية المدرجة بالخطط البحثية للأقسام البحثية المدروسة لمعهد بحوث الإرشاد الزراعي

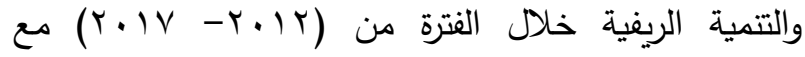
الأهداف العامة لإستراتيجية التمية الزراعية المستدامة

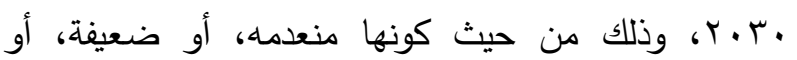
متوسطه، أو كبيره، أو كبيره جداً، ومعبراً عنها بقيم رقمية تتدرج من (1 إلى ه درجات) على الترتيب.

\section{الفروض البحثية}

استهدفت هذه الدراسة اختبار الفرض البحثي التالي: "توجد فروق مغزوية بين متوسطي تقدير المبحوثين للأهمية الحالية، وتقديرهم للأهمية المتوقعة للموضوعات

$$
\text { البحثية الإرشادية المدروسة ". }
$$

ويختبر هذا الفرض في صورته الصفرية التي تتص على: "لا توجد فروق مغزوية بين متوسطي تقدير المبحوثين

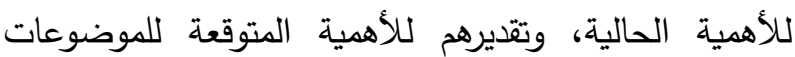

$$
\text { البحثية الإرشادية المدروسة ". }
$$


الإرشاد الزراعي والتتمية الريفية تتراوح من (0 إلى 0؛

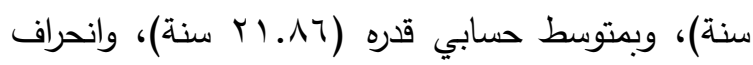
معياري قدره (^ سنة). وبتصنيف المبحوثين إلى ثلاث فئات وفقاً لسنوات خبرتهم باستخدام المتوسط والانحراف المعياري، تبين أن نسبة (r. 79\%٪) من المبحوثين قد

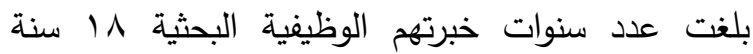
فأكثر، مما يتفق مع ما سبق عرضها من نتائج تتعلق

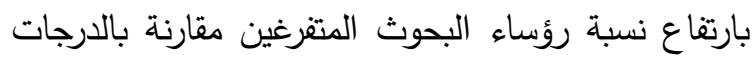
البحثية الوظيفية الأخرى داخل معهد بحوث الإشياد الزراعي والتتمية الريفية، ويشير ذلك إلى توفر الخبرة الوظيفية البحثية لغالبية المبحوثين من جهة، وأهمية ولنية استغلال هذه الخبرات الوظيفية البحثية في تأهيل الكوادر البحثية الثابة لتحقيق أهداف معهد بحوث الإرشاد الزراعي والتتمية الريفية المنشودة من جهة أخرى. 0ـ عدد البحوث المنشورة: أوضحت النتائج المبينة بجدول (1) (أن عدد البحوث المنشورة للمبحوثين تراوحت من (1)

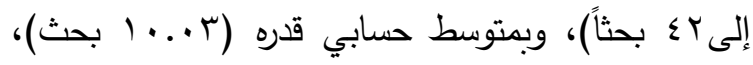

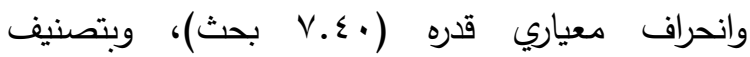
المبحوثين وفقاً لعدد بحوثهم المنشورة وفقا للمتوسط والانحراف المعياري إلى ثلاث فئات، وقد بلغت نسبة من تقل عدد بحوثهم المنشورة عن 7 بحوث (·ץ\%)، ومن

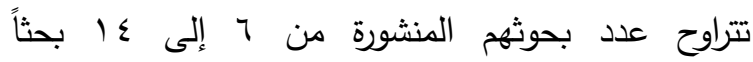

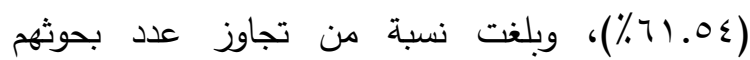

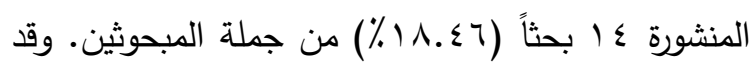
اشارت البيانات إلى ارتفاع عدد البحوث المنشورة لدى (^^) من المبحوثين، مما يعكس بوضوح وفرة الإنتاج البحثي بمعهد بحوث الإرشاد الزراعي والتتمية الريفية،

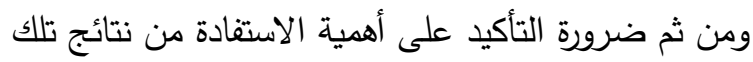
البحوث في عملية تطوير وتحديث العمل الزراعي عامه والإرشادي منه خاصه. ד- مستوى التدريب المهني: أظهرت النتائج الواردة بجدول

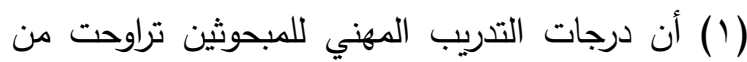

أساليب تحليل البيانات البحثية بعد جمع البيانات البحثية ومراجعتها، وتفريغها، وتبويبها، وجدولتها، وعمل التوزيعات التكرارية للبيانات البحثية بما يتفق والأهداف البحثية. وقد تم الاستعانة ببعض الأساليب الإحصائية مثل الجداول التكرارية، والنسب المئوية، والمتوسط الحسابي، والانحراف المعياري، والمدى، واختبار "ت" لقياس الفرق بين متوسطين T- test في تحليل بيانات البحث، وذلك

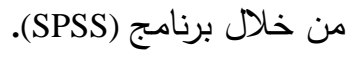
النتائج ومناقشتها أولاً: الخصائص الثخصية والمهنية للمبحوثين 1- السن: تثير النتائج بجدول (1) أن سن المبحوثين يتراوح من (Tr إلى /V سنة)، بمتوسط حسابي قدره (VV.7V سنة)، وانحراف معياري قدره (9.01 سنة)، وتم تصنيف المبحوثين وفقاً للمتوسط والانحراف المعياري إلى ثلاث فئات، وتثير تلك النتائج إلى أن الغالبية من المبحوثين

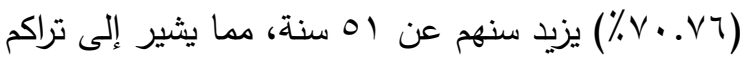
الخبرات لدى هؤلاء المبحوثين، ومن ثم قدرتهم على يرلى تطوير العمل البحثي الإرشادي. r- التخصص الوظيفي: أظهرت النتائج البحثية المبينة بدول (1) أن قرابة نصف عدد المبحوثين يعملون بقسم البرامج الإرشادية بمعهد بحوث الإرشاد الزراعي والتتمية الريفية، مما يشير إلى ضرورة إعادة التوازن بين الأقسام

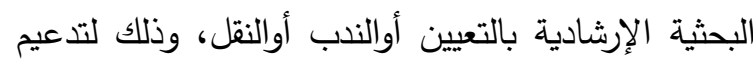
فعالية معهر بحوث الإرشاد الزراعي والتتمية الريغية في الإنيا تحقيق أهدافه المنشودة. r- الارجة الوظيفية البحثية: تعكس النتائج البحثية الواردة بجدول (1) ارتفاع نسبة رؤساء البحوث المتفرغين مقارنة بالدرجات البحثية الوظيفية الأخرى داخل معهد بحوث الإرشاد الزراعي والتتمية الريفية ع - الخبرة الوظيفية البحثية: أوضحت النتائج البحثية بجدول (1) أن عدد سنوات خبرة المبحوثين بالعمل بمعهد بحوث 
تتراوح من (7 إلى 1 (درجة)، وبمتوسط حسابي مقداره

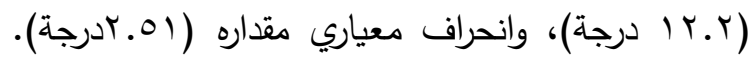
وبتصنيف المبحوثين وفقاً للمتوسط والانحراف المعياري إلى ثلاث فئات، فقد بلغت نسبة من يتسمون بمستوى

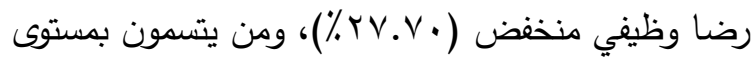

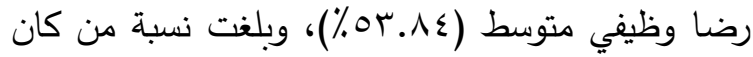

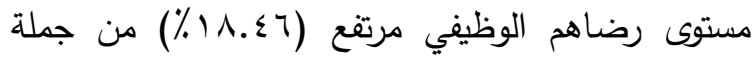

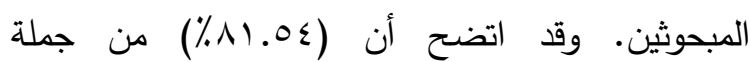
المبحوثين يتسمون بمستوى منخفض ومتوسط من الرضا

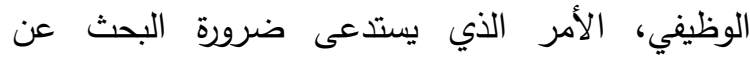
مسببات ذلك للتمكن من توفير المقومات اللازمة لتحقيق مقومات الرضا الوظيفي لاى هؤلاء المبحوثين.

rV. l ( إلى V) درجة)، وانحراف معياري قدره (VV.T درجة). وبتصنيف المبحوثين وفقاً للمتوسط والانحراف المعياري إلى ثلاث فئات، تبين أن نسبة من كان مستوى تدريهه المهني منخفض بلغت (YT. צY\%)، بينما بلغت نسبة من كان

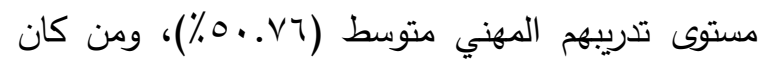
مستوى تدريبهم المهني مرتفع (با.ك؟ץ\%) من جملة المبحوثين. وتثير تلك البيانات إلى أن ما يزيد عن ثلاثة

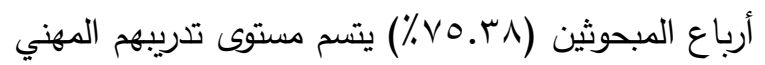
بالمتوسط والمنخفض، الأمر الذي يستلزم الاهتمام بعملية التدريب المهني للمبحوثين بمعهد بحوث الإرشاد الزراعي والتتمية الريفية لرفع كفاءتهم المهنية. V- مستوى الرضا الوظيفي: أظهرت النتائج البحثية الواردة في جدول (1) أن درجات الرضا الوظيفي للمبحوثين

جدول 1 ـ توزيع المبحوثين وفقاً لبعض خصائصهم المميزة $\%$ العدد الخصائص الخين

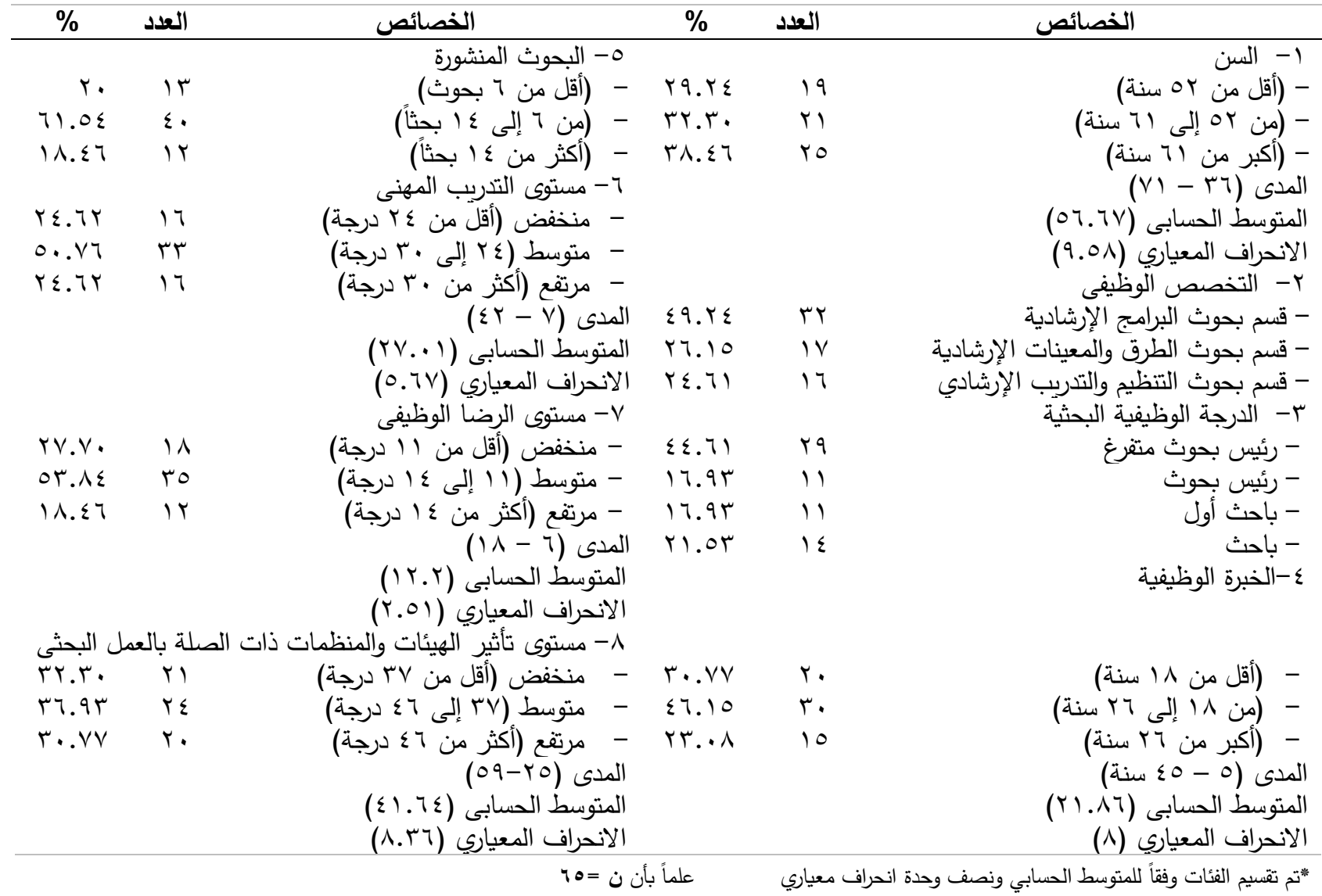


الزراعي والتتمية الريفية الثلاثة تبين أن عدد الموضوعات البحثية بقسم بحوث البرامج الإرشادية بلغ (7 (1) موضوعاً

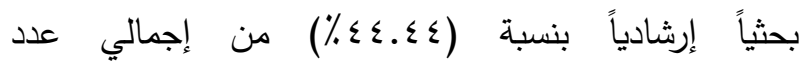
الموضوعات البحثية التي تم حصرها وتصنيفها، بينما بلغ عدد الموضوعات البحثية بقسم بحوث الطرق والمعينات

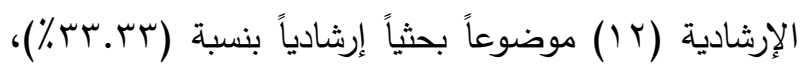
في حين بلغ عدد الموضوعات لقسم التتظيم والتتريب الإرشادي (^) موضوعات بحثية إرشادية بنسبة (r.r.r.r\%).

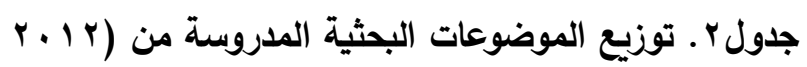

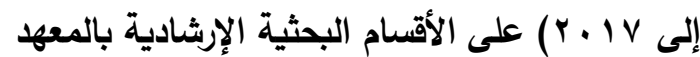

\begin{tabular}{|c|c|c|}
\hline$\%$ & 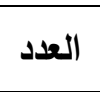 & القسم البحثي \\
\hline 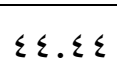 & 17 & بحوث البرامج \\
\hline Tr.rT & Ir & 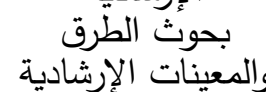 \\
\hline Th.tr & $\wedge$ & بحتوث التتظظيم \\
\hline $1 \ldots$ & דוץ & 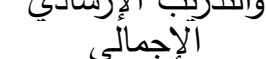 \\
\hline
\end{tabular}

وبتوزيع الموضوعات البحثية التي تم حصرها من الخطط

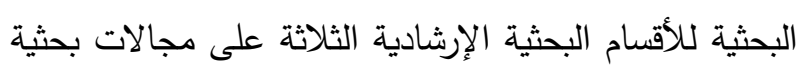

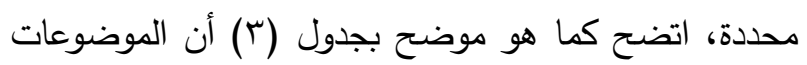
البحثية الإرشادية التي تناولها قسم بحوث البرامج الإرشادية تعقت بأربعة مجالات رئيسية: بناء برامج العمل الإرشادية الإدادي الإريادية في مختلف مجالات الإرشاد الزراعي وتتمية الموارد البيئية

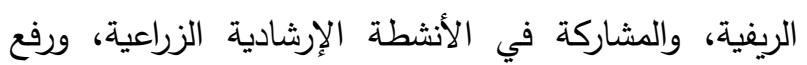

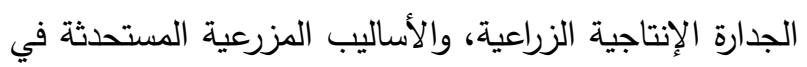

$$
\text { مختلف مجالات الإنتاج الزراعي. }
$$

A- مستوى تأثير الهيئات والمنظمات ذات الصلة بالعمل البحثي: تثير النتائج البحثية الواردة بجدول (1) إلى أن الن النيات

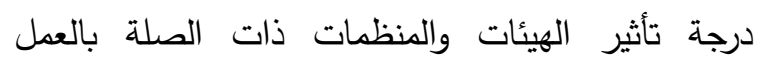
البحثي على عمل باحثي معهد بحوث الإرشاد الزراعي

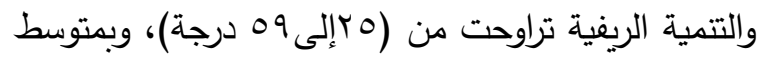

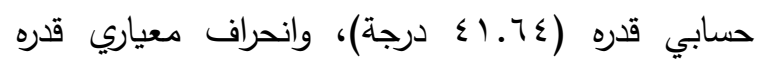

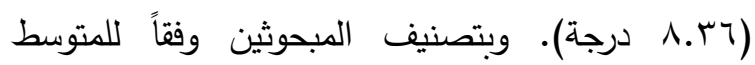

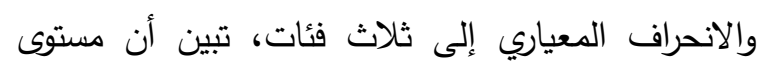

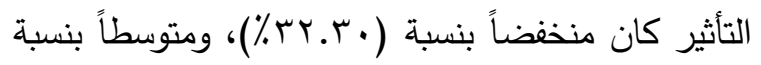

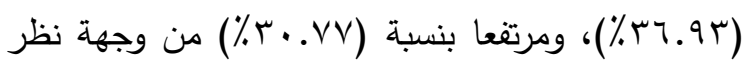
المجحوثين. كما أظهرت النتائج أن نسبة (rr.

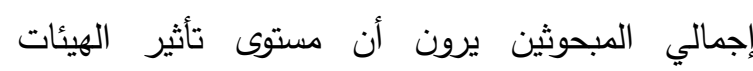

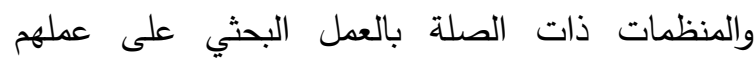

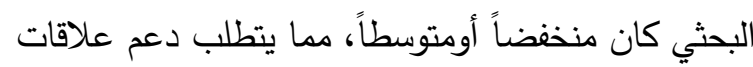
معهد بحوث الإرشاد الزراعي والتتمية الريفية بالهيئات والمنظمات ذات الصلة بالعمل البحثي الإرشادي.

ثانياً: حصر الخطط البحثية لمعهل بحوث الإرشاد الزراعي

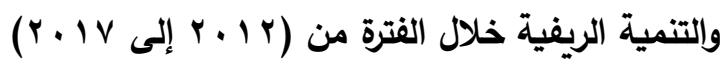

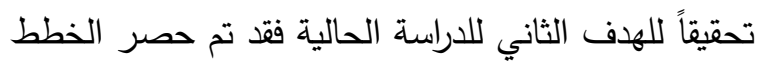
البحثية لمعهد بحوث الإرشاد الزراعي والتتمية الريفية خلال

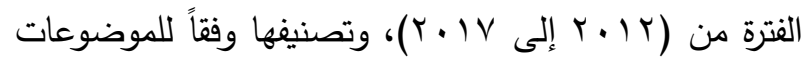
البحثية الإرشادية لأقسام معهد بحوث الإلى لإثاد الزراعي والتتمية الريفية (قسم بحوث البرامج الإرشادية، وقسم بحوث لإنداد الطرق والمعينات الإرشادية، وقسم بحوث التتظيم والتتريب). ويوضح جدول (r) أن إجمالي عدد الموضوعات البحثية الإنية

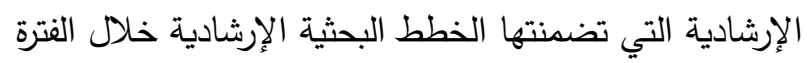

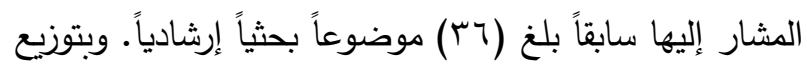
تلك الموضوعات البحثية على أقسام معهر بحوث الإرشاد 
جدول r. توزيع الموضوعات البحثية لقسم بحوث البرامج الإرشادية وفقاً لمجالاتها البحثية

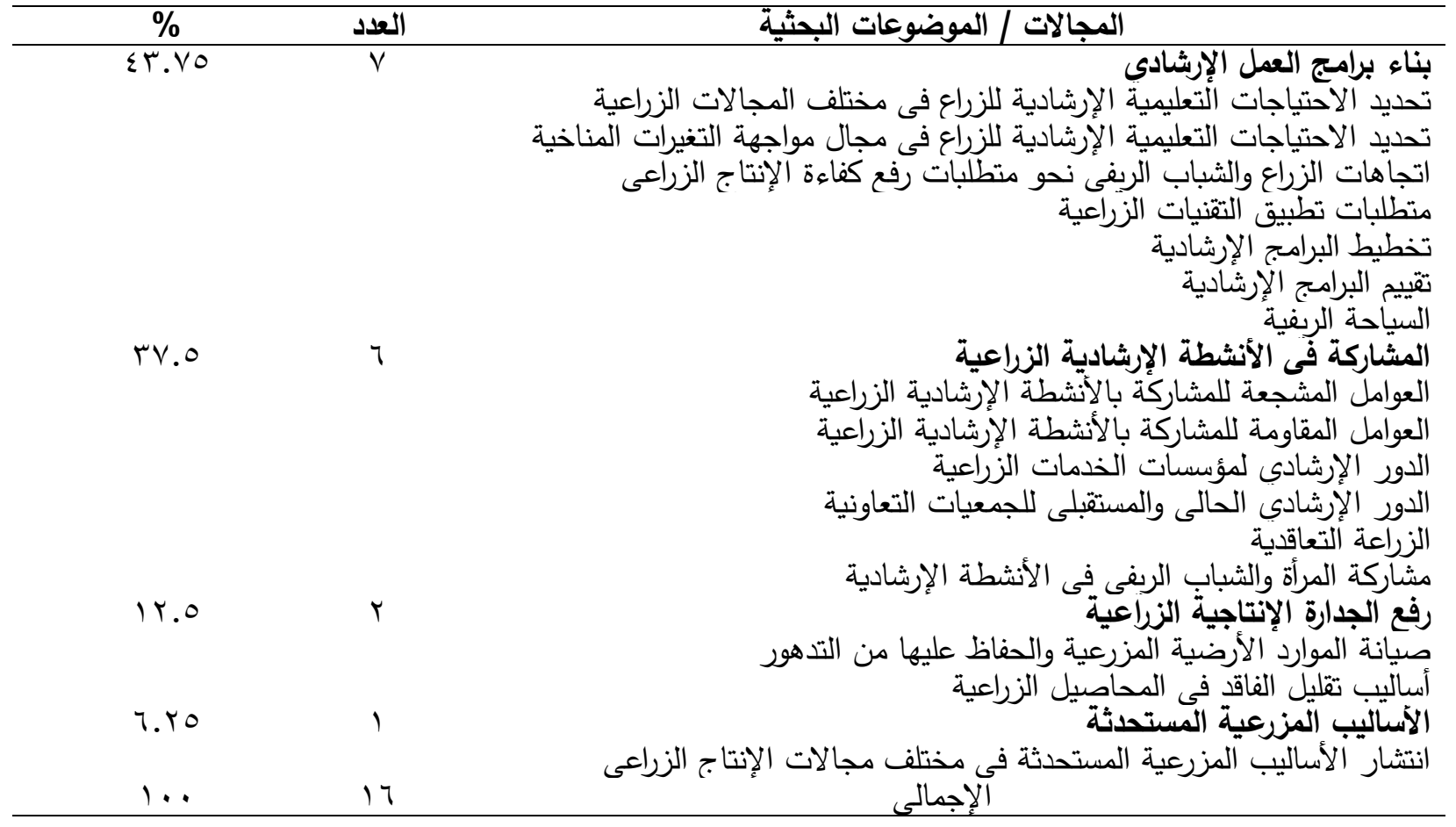

الأنثطة الإرشادية، والقيادة الريفية، وكفاءة وفاعلية المعينات

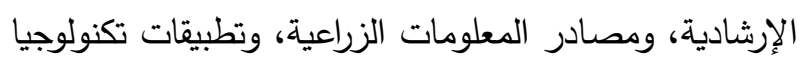

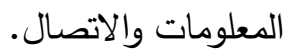

كما تبين النتائج بجدول (ع) بأن الموضوعات البحثية

لقسم بحوث الطرق والمعينات الإرشادية تعلقت بخمسة

مجالات رئيسية: كفاءة وفاعلية الطرق الإرشادية في تنفيذ

جدول ـ. توزيع الموضوعات البحثية لقسم الطرق والمعينات الإرشادية وفقاً لمجالاتها البحثية

\begin{tabular}{|c|c|c|}
\hline$\%$ & العدد & المجالات / الموضوعات البحشية \\
\hline ro & $r$ & 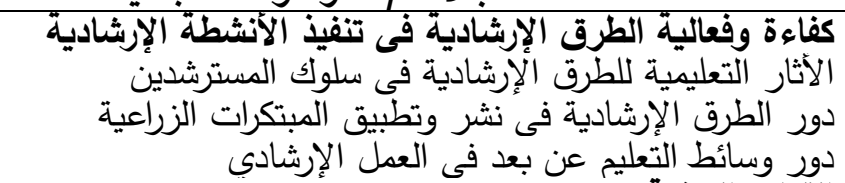 \\
\hline ro & r & 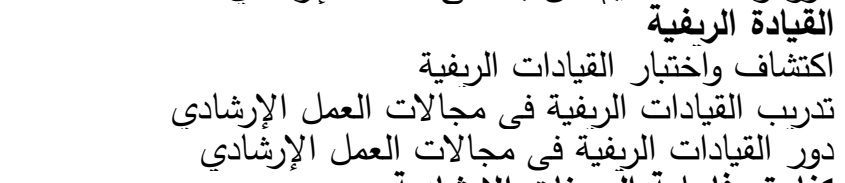 \\
\hline $17.7 \mathrm{~V}$ & r & 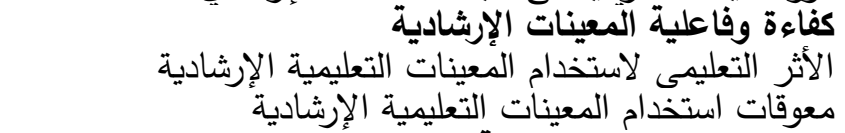 \\
\hline $17.7 \mathrm{~V}$ & r & 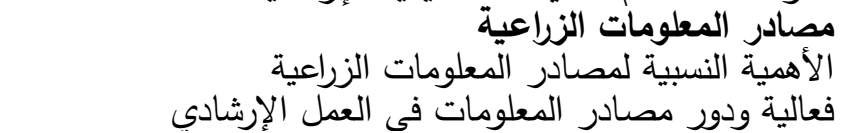 \\
\hline $17.7 \mathrm{~V}$ & Ir & 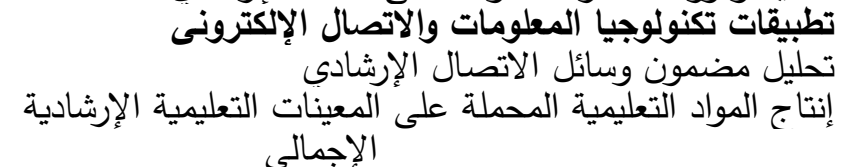 \\
\hline
\end{tabular}


جدول ه. توزيع الموضوعات البشثية لقسم التنظيم والتدريب الإرشادي وفقاً لمجالاتها البحثية

\begin{tabular}{|c|c|c|}
\hline$\%$ & العدد & المجالات /الموضوعات البحثية \\
\hline ro & r & 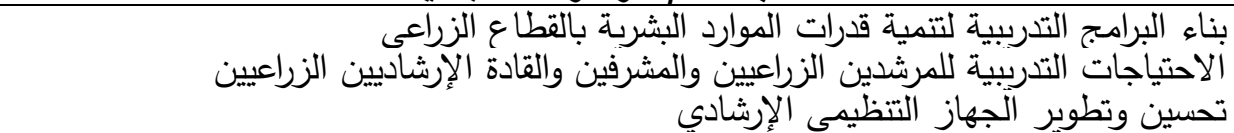 \\
\hline ro & r & 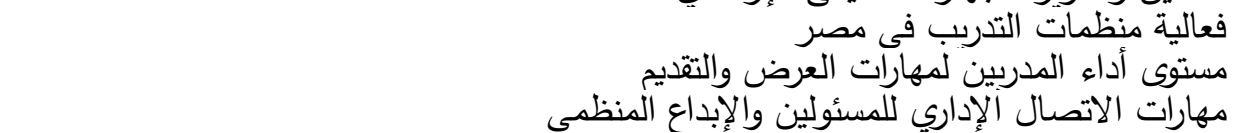 \\
\hline ro & r & إداد الزراعى ذات العلاقة بالنشاط الزراعى \\
\hline 14.0 & 1 & 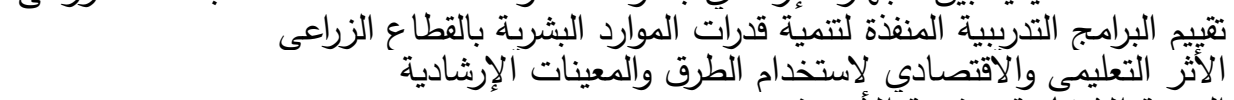 \\
\hline 14.0 & 1 & 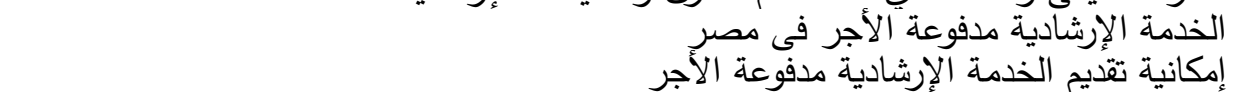 \\
\hline $1 \ldots$ & $\Lambda$ & \\
\hline
\end{tabular}

البحثية بجدول (T) أن درجة الأهمية الحالية للموضوعات

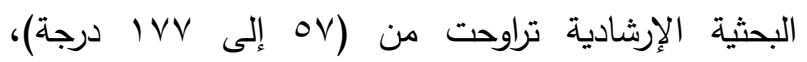

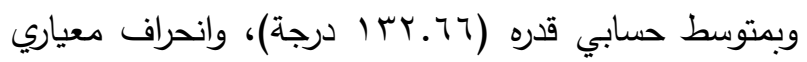

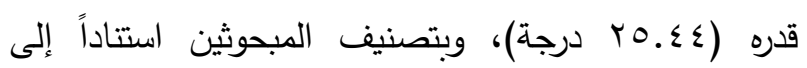

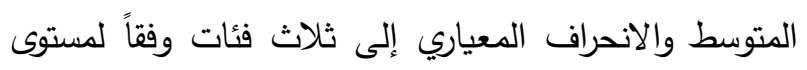

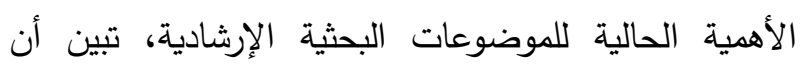

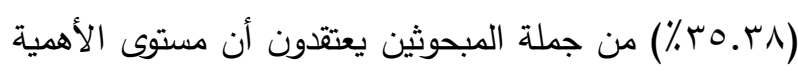

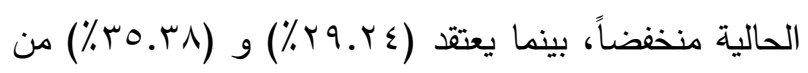
جملة المبحوثين أنه مستوى متوسطاً أو مرتفعاً على الترتيب.

جدول جا توزيع المبحوثين وفقاً لفئات مستوى الأهية الحالية للموضوعات البحثية الإرشادية من وجهة نظرهم

\begin{tabular}{|c|c|c|}
\hline$\%$ & العدد & الأهئات مستولة الحالية \\
\hline ro.r & $r$ & من · r با درجة (آقل) \\
\hline rq. & 19 & 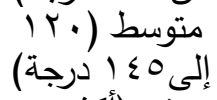 \\
\hline N & rr & مرتفع (آكثر من \\
\hline $1 \ldots$ & 70 & الاحمال \\
\hline
\end{tabular}

وتوضح النتائج البحثية بجدول (0) أن الموضوعات البحثية التي تتاولها قسم بحوث التتظيم والتدريب الإرشادي تعلقت بخمسة مجالات بحثية: بناء البرامج التدريبية لتتمية التئية قدرات الموارد البشرية بالقطاع الزراعي، وفعالية منظمات

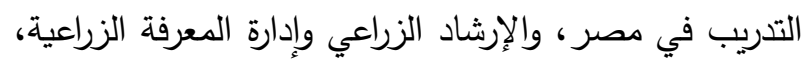

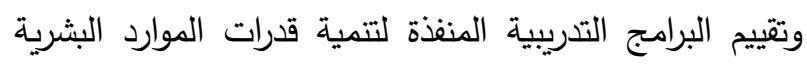

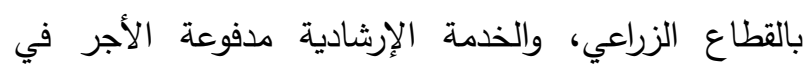
مصر

ثالثاً: تحديد مستوى الأهية الحالية والمتوقعة للموضوعات البحثية الإرشادية

تم الاستتاد في تقدير الأهمية الحالية والمتوقعة للموضوعات البحثية الإشادية من وجهه نظر المبحوثين

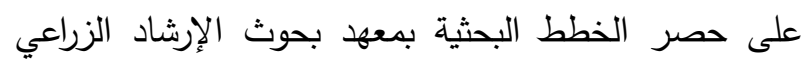

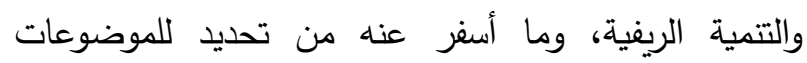
البحثية التي تضمنتها تلك الخطط البحثية، وفى هذا الصدد الترنات

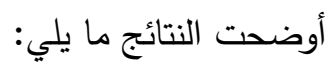
1- المستوى الأهمية الحالية بسؤال المبحوثين عن تقديراتهم الذاتية لدرجة الأهمية الحالية

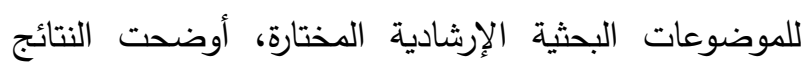


متطلبات تطبيق التقنيات الزراعية، وأساليب تقليل الفاقد في المحاصيل الزراعية.

كما توضح النتائج البحثية بجدول (V) أن الموضوعات البحثية الإششادية التي احتلت المراتب العشرة الأخيرة من

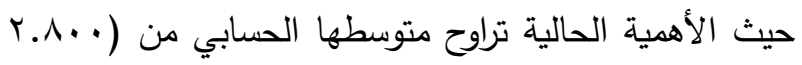
درجة إلى ب00. ب درجة)، وتلك الموضوعات هي: السياحة الريفية، وإمكانية تقديم الخدمة الإرشادية مدفوعة الأجر ، ودور وسائط التعليم عن بعد في العمل الإششادي، ومستوى أداء المدربين لمهارات العرض والتقديم، والدور الإرشادي الحالي والمستقبلي للجمعيات التعاونية، والدور الإرشادي لمؤسسات الخدمات الزراعية، والعلاقات التنظيمية بين مكونات النظام المعرفي والإرشاد الزراعي، ومهارات الاتصال الإداري للمسئولين والإبداع المنظمى، وتقييم البرامج التدريبية المنفذة لتمية قدرات الموارد البشرية، والعلاقات التتظيمية بين الجهاز الإرشادي بالمؤسسات والمنظمات. وربما ترجع المرتبة المتقدمة التي احتلتها الموضوعات البحثية الإرشادية من حيث الأهمية الحالية، لسهولة تطبيق نتائجها في الواقع العملي والتطبيقي، ولأنها تمس العملية التعليمية الإرشادية بثكل مباشر، في حين أن تطبيق نتائج الموضوعات البحثية الإرشادية التي جاءت في مرتبة متأخرة تحتاج إلى المزيد من التسيق بين المؤسسات والهيئات ذات الصلة بالعمل البحثي الإرشادي.
وتثير تلك النتائج إلى أن ثلثي المبحوثين تقريباً

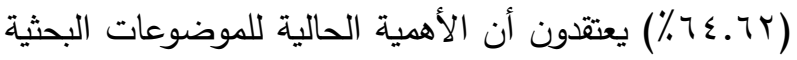
إما منخفضة أو متوسطة، وربما يرجع ذلك إلى الاعتقاد بعدم جدوى البحوث، والتخوف من التعرض لبحوث تحمل المخاطرة في تتفيذها ونتائجها، أو لضعف الإمكانيات المادية المتوافرة للباحثين.

ولمزيد من التوضيح تم الاستتاد إلى تقدير المتوسط الحسابي لدرجة الأهمية الحالية لكل من تلك الموضوفي التهات البحثية الإرشادية المدروسة، والذي في ضوئه أمكن ترتيبها وفقاً لأهميتها الحالية من وجهه نظر المبحوثين .وتوضح النتائج البحثية بجدول (V) أن الموضوعات البحثية الإرشادية التي احتلت المراتب العشرة الأولى من حيث الأهمية الحالية

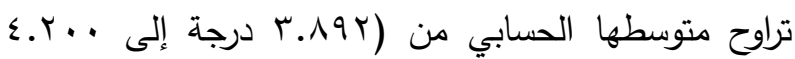
درجة)، وتلك الموضوعات هي: تحديد الاحتياجات التعليمية الإرشادية للزراع في مختلف المجالات الزراعية، والاحتياجات التدريبية للمرشدين الزراعيين والقادة، ودور الطرق الإرشادية في نشر وتطبيق المبتكرات الزراعية، وتحديد الاحتياجات التعليمية الإششادية للزراع في مجال التغيرات المناخية، وفعالية ودور مصادر المعلومات في العمل الإرشادي، وانتشار الأساليب المزرعية المستحدثة، وتخطيط البرامج الإرشادية لفئات المختلفة المستهدفة، وصيانة الموارد الأرضية المزرعية والحفاظ عليها من التدهور، ودراسة 
جدول V. ترتيب الموضوعات البحثية وفقاً لأهميتها الحالية من وجهه نظر المبحوثين

\begin{tabular}{|c|c|c|c|}
\hline الترام & 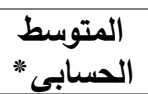 & إجمالي القيمّم المعبرة & عات البحثية الإرشادية \\
\hline 1 & $\varepsilon . Y_{.}$ & TVT & م مختلف المجالات الزراعية \\
\hline r & $\varepsilon .1 \Gamma \wedge$ & Y7q & الاحتياجات الت \\
\hline$r$ & $\varepsilon . .9 T$ & YTY & دور الطرق الإ \\
\hline$\varepsilon$ & $r .90 r$ & rov & تحديد الاحتياجات التعليمية | \\
\hline 0 & r.qT人 & roT & فعاليّة ودورِ مَصادر المَعلتوما \\
\hline 7 & r.9r人 & Y0T & انتشار الأسناليب \\
\hline$\checkmark$ & r.qrr & roo & تخطيط البرامج الإ \\
\hline$\wedge$ & r.qr & roo & صيانة الموارد \\
\hline 9 & $r .9 \cdot V$ & Tos & دراسية متطلبات \\
\hline 1. & r.A9r & ror & أساليب تقليل \\
\hline 11 & $r . \wedge \leq 7$ & ro. & الأهمية النسبية لم \\
\hline ir & r.Ar. & $r \leqslant q$ & الزراعة التعاقد \\
\hline r & r.A10 & $r \leqslant \wedge$ & الأثار التعليمية \\
\hline $1 \leq$ & r.A10 & $r \leqslant \wedge$ & مشاركة المرأة وا \\
\hline 10 & T.VTr & $r \leqslant r$ & تقييم البرامج الإرة \\
\hline 17 & T.VTr & $r \leqslant r$ & فى مجالات العمل الإرشادي \\
\hline iv & $r . v \cdot v$ & $r \leqslant 1$ & معوقات استخدام المعينات الإرشادية \\
\hline 11 & $r . v \cdot v$ & $r \leqslant 1$ & كة الإنتاج الزراعي \\
\hline 19 & r.79r & r $\varepsilon$. & إنتاج المواد الن \\
\hline r. & T.74) & rTh & الأثر التعليمى لا \\
\hline r) & $T .7 \leq 7$ & rTV & العوامل المقاومة \\
\hline rt & ז.7. & דוr & الات العمل الإرشادي \\
\hline rt & r. & rmi & اكتشاف وإختيار الذَ \\
\hline$r \varepsilon$ & $r .710$ & rto & تحليل مضمون وسائل الاتصآل الإرشادي \\
\hline ro & $T .0 \wedge \varepsilon$ & rra & تحسين وتطوير الجهاز التظيمى الإرشاديّي \\
\hline rч & $r .079$ & rtr & العوامل المشجن \\
\hline rV & r.00r & rm & العلاقات التظظيمية بين الجهاز الإرشادي بالمؤسسات والمنظمات \\
\hline rᄉ & r.orr & rrq & تقييم البرامج التدريبية المنفذة لتنمية قدرات الموارد البشرية \\
\hline rq & r.orr & rrq & مهارات الاتصال الإداري للمسئولين "والإبداع المنظمى . \\
\hline$r \cdot$ & $\mathrm{r} .0 \cdot \mathrm{V}$ & rrA & العلاقات التنظيمية بين مكونات النظام المعرفي والإرشّاد \\
\hline r & r. $\leqslant q r$ & rTV & الاور الإرشادي لمؤسسات الخد \\
\hline rt & r. $\leqslant \vee \tau$ & rYT & الدور الإرشادي الحالى والمستقبلى للجمعيات التعاونية \\
\hline r & r.rqr & Y) $\leq$ & مستوى أداء المدربين لمهارات العرض والتقديم \\
\hline$r \varepsilon$ & r.r. & r). & دور ويائط التعليم عن بعد في العمل الإرشادي \\
\hline ro & r.lor & r.o & إمكانية تقديم الخدمة الإرشادية مدفوعة الأجر \\
\hline r & r.A.. & lat & ألسياحة الريفية \\
\hline
\end{tabular}

"المتوسط الحسابي عباره عن إجمالي القيم المعبرة عن الأهمية الحالية مقسوماً على عدد العينة (70)

معياري قدره (r.A.؟r درجة)، وبتصنيف المبحوثين استتاداً

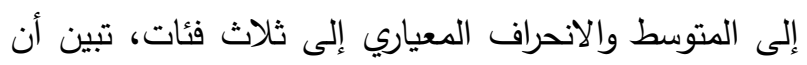

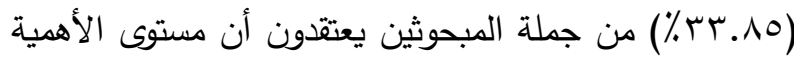

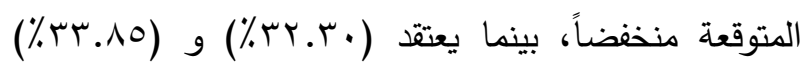

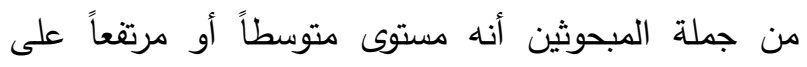
الترتيب.

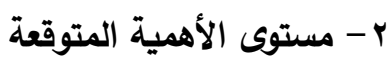
بيؤال المبحوثين عن تقديراتهم الذاتية لارجة الأهمية المتوقعة للموضوعات البحثية الإرشادية المختارة، أوضحت

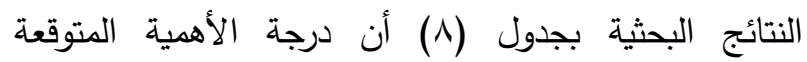

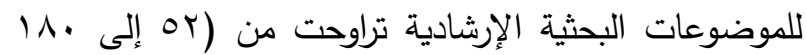

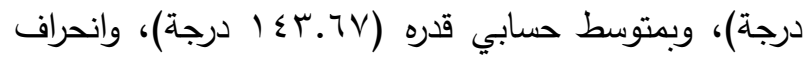


وتحديد الاحتياجات التعليمية الإرشادية للزراع في مجال التغيرات المناخية، وتخطيط البرامج الإرشادية للفئات المختلفة المستهدفة، وانتشار الأساليب المزرعية المستحدثة، ودراسة ونيطة متطلبات تطبيق التقنيات الزراعية، والآثار التعليمية للطرق الإرشادية في سلوك المرشدين، وصيانة الموارد الأرضية المزرعية والحفاظ عليها من التدهور ، وأساليب تقليل الفاقد في

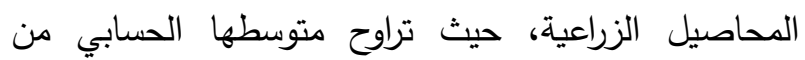

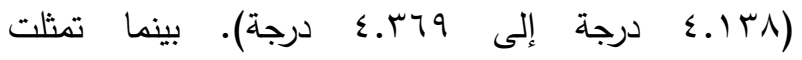
الموضوعات البحثية الإرشادية التي احتلت الترتيب المتدني وفقاً لأهميتها المتوقعة في: السياحة الريفية، ودور وسائط الإنطايه التعليم عن بعد في العمل الإرشادي، والدور الإرشادي الحالي والمستقبلي للجمعيات التعاونية، والدور الإرشادي لمؤسسات الخدمات الزراعية، ومستوى أداء المدربين لمهارات العرض الهاب والتقديم، والعوامل المقاومة للمشاركة بالأنشطة الإرشادية الزراعية، ومعوقات استخدام المعينات الإرشادية، واتجاهات الزراع والثباب الريفي نحو متطلبات رفع كفاءة الإنتاج الزراعي، والعلاقات التنظيمية بين مكونات النظام المعرفي والإرشاد الزراعي، ومهارات الاتصال الإداري للمسئولين والإبداع المنظمى، حيث تراوح متوسطها الحسابي من

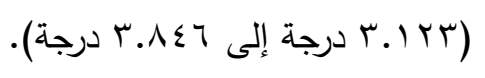

جدول ^. توزيع المبحوثين وفقاً لفئات مستوى الأهمية المتوقعة للموضوعات البحثية الإرشادية من وجهة نظرهم

\begin{tabular}{|c|c|c|}
\hline$\%$ & العدد & الأهمية المتوقية مستوي \\
\hline rr.Ao & Tr & منخفض (آقل من \\
\hline r.r.r. & YI & متوسط (1) إلى 104) \\
\hline ס..r & YY & مرتفع (أكثر من \\
\hline $1 \ldots$ & 70 & الجملة \\
\hline
\end{tabular}

وتشير تلك النتائج أن ثلثي المبحوثين تقريبا (0 ــ7\%) يعتقدون أن الأهمية المتوقعة للموضوعات البحثية متوسطة النتانيز ومرتفعة.

ولمزيد من التوضيح يمكن استعراض بيانات الجدول (9)، والتي أوضحت ترتيب الموضوعات البحثية وفقاً لمتوسط ليط لئرن أهميتها المتوقعة من وجهه نظر المبحوثين. وتبين النتائج أن الموضوعات البحثية الإرشادية التي احتلت المراتب العشرة الأولى من حيث الأهمية المتوقعة تمثلت في: الاحتياجات التدريبية للمرشدين الزراعيين والقادة، وتحديد الاحتياجات التعليمية الإرشادية للزراع في مختلف المجالات الزراعية، ودور الطرق الإرشادية في نشر وتطبيق المبتكرات الزراعية، 
جدول 9 ـ ترتيب الموضوعات البحثية وفقاً لأهميتها المتوقعة من وجهه نظر المبحوثين

\begin{tabular}{|c|c|c|c|}
\hline الترتيب العام & الحسابى * المتط & عَ الأهمية القيم المتوقعةة & الموضوعات البحثية الإششادية \\
\hline 1 & $\varepsilon . r 79$ & 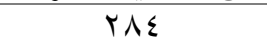 & الاحتياجات التدرببية للمرشد \\
\hline r & E.ror & rᄉr & ف المجالات الزراعية \\
\hline r & 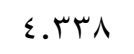 & rAr & دور "الطرق "الإرشاد. \\
\hline$\varepsilon$ & E.TYT & 怾 & ل التغيرات المناخية \\
\hline 0 & $\varepsilon . r \cdot V$ & rA. & تخطيط البرامج الإرة \\
\hline 7 & E.YqY & rVq & انتشار الأساليب ألمز \\
\hline$\checkmark$ & E.rVT & TVA & دراسة متطلبات تط \\
\hline$\wedge$ & $\varepsilon .10 r$ & rV. & الأثار التعليمية للد \\
\hline 9 & $\varepsilon .1 T \Lambda$ & หาq & صيانة الموارد الأرص \\
\hline 1. & E.) & r49 & أساليب تقليل الفاقة \\
\hline 11 & ש.וT & หฯA & الزراعة التعاقدية \\
\hline ir & $\varepsilon .94$ & Y74 & فعالية ودور مصادر المعلوماد \\
\hline ir & $\varepsilon . \cdot \vee \uparrow$ & r7o & الأهمية النس \\
\hline $1 \varepsilon$ & $\{\ldots+7)$ & YTร & الأثر التعليمى \\
\hline 10 & $\varepsilon . \cdot r$. & rTt & للفئات" المختلفة آمستَهدفة \\
\hline 17 & $\varepsilon .+10$ & YTI & دور القيادات الربفية فى مجالات العمل الإرشادي \\
\hline iv & $\varepsilon . \cdot 10$ & YT) & اكتشاف واختب \\
\hline 11 & $\varepsilon \ldots$ & זч. & 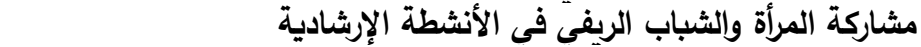 \\
\hline 19 & $r .9 \wedge \varepsilon$ & roq & ـ الجّهاز الإرشادي بالمؤَسسات والمنظمات \\
\hline r. & $r .9 \mu \wedge$ & ror & تحسين وتطوبر \\
\hline r) & r.9rt & roo & 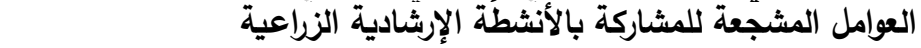 \\
\hline tr & $r .9 \cdot v$ & Yos & تحليل مضمون وسائل الاتصال الإرشادي \\
\hline r & r.AVT & ror & تقييم البرامج التدرببية المنفذة لتنمية قدرات الموارد البشربة \\
\hline$r \varepsilon$ & ケ.Ат! & rol & إنتاج المواد التعليمية المحملة \\
\hline ro & r.АTI & rol & أمكانية تقديم الخدمة الإرشادية مدفوعة الأج \\
\hline rq & $\Gamma . \wedge \leqslant 7$ & ro. & تُدربب القيادات الريفية في مجالات العمل الإرشادي \\
\hline rV & $r . \wedge \leqslant 7$ & ro. & مهآرات الاتصال الإداري للمسئولين والإبداع المنظمى \\
\hline rᄉ & r.یr. & $r \leqslant 9$ & العلاقات التظيمية بين مكونات النظام المعرفى والإرشَاد الزراعى \\
\hline rq & r.人ץ. & $r \leqslant 9$ & اتجاهات الزراع وإلثباب الريفى نحو متطلبات رفع كفاءة الإنتاج الزراعى \\
\hline r. & r.А.. & $r \leqslant V$ & معوقات استخدام المعينات الإرشّادية \\
\hline$\mu^{1}$ & r.^.. & $r \leqslant V$ & العوامل المقاومة للمشّاركة بأَأنثشظة الإرشادية الزراعية \\
\hline rt & r.^.. & $r \leqslant V$ & مستوى أداء المدربين لمهارات العرض والتقديم \\
\hline r & r.^.. & $r \leqslant V$ & الدور الإرشادي لمؤسسات الخدمات الزراعية \\
\hline$r \varepsilon$ & r.จฯq & $r \leqslant 0$ & الدور الإرشادي الحالى والمستقبلى للجمعيات التعاونية \\
\hline ro & r.vr人 & $r \leqslant r$ & دور وسيائط التعليم عن بعد فى العمل الإرشادي \\
\hline צ & מזוני & r. T & السياحة الربفية \\
\hline
\end{tabular}

"المتوسط الحسابي عباره عن إجمالي القيم المعبرة عن الأهمية المتوقعة مقسوماً على عدد العينة (70)

الزراعيين والقادة، ودور الطرق الإرشادية في نشر وتطبيق المبتكرات الزراعية، وتحديد الاحتياجات التعليمية الإرشادية للزراع في مجال التغيرات المناخية، وانتشار الأساليب المزرعية المستحدثة، وتخطيط البرامج الإرشادية للفئات المختلفة المستهدفة، وصيانة الموارد الأرضية المزرعية الإسية ولهاه
وتثير النتائج وفقاً لجدولي (V) و (9) أن هناك اتفاقاً بين التقدير الذاتي للمبحوثين للأهمية الحالية والأهمية المتوقعة للموضوعات البحثية الإرشادية التي احتلت ترتيباً متقدماً وهى: تحديد الاحتياجات التعليمية الإرشادية للزراع في مختلف المجالات الزراعية، والاحتياجات التدرببية للمرشدين 
كما تبين أيضا وجود فروق مغزوية عند المستوى الاحتمالي ه .. ب. بين متوسطات الأهمية الحالية والأهمية المتوقعة للموضوعات البحثية الإرشادية التالية: تخطيط البرامج الإرشادية للفئات المختلفة المستهدفة، ودراسة متطلبات تطبيق التقنيات الزراعية، وتقييم البرامج التدرببية المنفذة لتتمية قدرات الموارد البشرية، والزراعة التعاقدية، وتحسين وتطوير الجهاز التظيمي الإشادي الزراعي، وتقييم البرامج الإرشادية للفئات المختلفة المستهدفة، ومهارات الاتصال الإداري للمسئولين والإبداع المنظمى، وتحليل مضمون وسائل الاتصال الإرشادي، ودور القيادات الريفية في مجالات العمل الإرشادي، والسياحة الريفية. بالإضافة لما سبق لم يتبين وجود أي فروق مغزوية بين

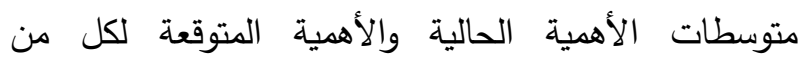
الموضوعات البحثية الإششادية الأتية: الأهمية النسبية لمصادر المعلومات الزراعية، وفعالية ودور مصادر المعلومات في العمل الإرشادي، وتحديد الاحتياجات التعليمية الإرشادية للزراع في مختلف المجالات الزراعية، ودور الطرق الإرشادية في نشر وتطبيق المبتكرات الزراعية، والاحتياجات التدريبية للمرشدين الزراعيين والقادة، وإنتاج المواد التعليمية المحملة على المعينات التعليمية الإششادية، والعوامل المقاومة للمشاركة بالأنشطة الإرشادية الزراعية، والدور الإششادي الحالي والمستقبلي للجمعيات التعاونية، وتدريب القيادات الريغية في مجالات العمل الإرشادي، والعلاقات التتظيمية بين مكونات النظام المعرفي والإششاد الزراعي، والدور الإرشادي لمؤسسات الخدمات الزراعية، ومشاركة المرأة والثباب الريفي في الأنشطة الإرشادية، وصيانة الموارد الأرضية المزرعية والحفاظ عليها من التدهور، وأساليب تقليل الفاقد في المحاصيل الزراعية، ومعوقات استخدام المعينات الإشادية، ودراسة اتجاهات الزراع والثباب الريفي نحو متطلبات رفع كفاءة الإنتاج الزراعي. وتؤكد هذه النتائج إلى وتى ضرورة التركيز المستقبلي على الموضوعات البحثية
والحفاظ عليها من التدهور، ودراسة متطلبات تطبيق التقنيات الزراعية، وأساليب تقليل الفاقد في المحاصيل الزراعية. في حين كان هناك اتفاقاً بين التقدير الذاتي للمبحوثين للأهمية الحالية والأهمية المتوقعة للموضوعات البحثية الإرشادية التي احتلت ترتيباً متدنياً وهي: السياحة الريفية، ودور وسائط التعليم عن بعد في العمل الإرشادي، ومستوى أداء المدربين وهني لمهارات العرض والتقديم، والدور الإرشادي الحالي والمستقبلي للجمعيات التعاونية، والدور الإرشادي لمؤسسات الخدمات الزراعية، والعلاقات التتظيمية بين مكونات النظام المعرفي والإرشاد الزراعي، ومهارات الاتصال الإداري للمسئولين والإبداع المنظمى.

مغزوية الفروق بين متوسطات مستوى الأهمية الحالية والمتوقعة للموضوعات البحثية الإرشادية المدروسة: ولاختبار مغزوية الفروق بين كل من المتوسطات الحسابية المعبرة عن أهمية الوضع الحالي للموضوعات البحثية الإرشادية، ونظيرتها المعبرة عن أهمية الوضع المتوقع من وجهة نظر المبحوثين كما هو موضح بجدول (• (1)، تم استخدام اختبار (ت) والذى تبين منه وجود فروق مغزوية عند المستوى الاحتمالي ال... بين متوسطات الأهمية الحالية والأهمية المتوقعة لكل من الموضوعات البحثية الإرشادية الآتية: إمكانية تقديم الخدمة الإرشادية مدفوعة الأجر، ومستوى أداء المدربين لمهارات العرض والتقديم، والأثار التعليمية للطرق الإرشادية في سلوك المرشدين، والعوامل المشجعة للمشاركة بالأنشطة الإرشادية الزراعية، والأثر التعليمي لاستخدام المعينات التعليمية الإرشادية، ودور وسائط التعليم عن بعد في العمل الإششادي، وتحديد الاحتياجات التعليمية الإرشادية للزراع في مجال التغيرات المناخية، وانتشار الأساليب المزرعية المستحدثة، واكتشاف الهن واختيار القيادات الريغية، والعلاقات التتظيمية بين الجهاز الإرشادي بالمؤسسات والمنظمات. 
الإششادية التي تثير إلى ارتفاع الأهمية المتوقعة، ومن ثم ثبت مغزوية الفروق بين متوسط تقدير المبحوثين لأهميتها الحالية والمتوقعة. والذي ينص على " توجد فروق مغزوية توجيه العمل البحثي الإرشادي المأمول استهدافه مستقبلاً. بين متوسطي تقدير المبحوثين للأهمية الحالية، وتقديرهم للأهمية المتوقعة للموضوعات البحثية الإرشادية المدروسة ". في ضوء النتائج التي توصلت إليها الدراسة فإنه يمكن رفض الفرض الصفري جزئياً، ومن ثم إمكانية قبول الفرض البديل جزئياً فيما يتعلق بالموضوعات البحثية الإرشادية التي

جدول • ـ ـ مغزوية الفروق بين متوسطات مستوى الأهمية الحالية والأهمية المتوقعة للموضوعات البحثية الإرشادية المدروسة

\begin{tabular}{|c|c|c|c|c|}
\hline الدلالة الإحصائية & قيمة & اللأهميّية & اللأهسابي الحتية & شيادية \\
\hline$(\cdot . \cdot 1)$ & r.乏ץᄉ & E.10r & $r .110$ & التعليمي \\
\hline$(\cdot .1)^{\prime}$ & r.r.. & r.9rT & $r .079$ & العوامل المشجعة \\
\hline$(. .00)$ & שT.T. & E.lזr & r.Аr. & ة التعاقة: \\
\hline$(\cdot .1)^{\prime}$ & r.IVV & r.VTh & r.r. & دور وسائط الت \\
\hline غَير دال & $1 . \wedge T V$ & $\varepsilon . \cdot V \uparrow$ & $\Gamma . \wedge \leq 7$ & الأهمب \\
\hline غير دال & 1.rrq & $\varepsilon .99$ & r.9५ & فعالية ودور \\
\hline$(\cdot .0)$ & 1.994 & $r .9 \cdot V$ & $r .710$ & تحليل مضمون \\
\hline غ غُير دال & 1.10 & E.ror & $\varepsilon . r_{.}$ & تحليد الاحتياجات التعليمية الإ \\
\hline$(\cdot . \cdot)$ & r...9V & 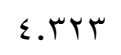 & r.90r & ل التغيرات المناخية \\
\hline غَير دال & $1 . \wedge V$. & 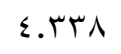 & $\varepsilon .99$ & دور الطرق الأ \\
\hline غير دال & $1 . \wedge 11$ & $\varepsilon .479$ & $\varepsilon .1 \mu_{\Lambda}$ & الاحتياجات الi \\
\hline$(\cdot .0)$ & r. $\leqslant 90$ & E.YVT & $r .9 \cdot V$ & دراسة متطلبات \\
\hline$(. .0)^{\prime}$ & T.TTE & $\varepsilon . r \cdot V$ & r.qrT & تخطيط البرامـج الإ \\
\hline$(. .00)$ & T.MYI & $\varepsilon . \cdot r$. & T.VTr & تقييم البرامج الإرشًا \\
\hline غُير دال & $1 . M T$ & r.Ат! & r.79r & إنتاج المواد التعليمية الت الماد \\
\hline$(\cdot .00)$ & 1.910 & r.IrT & r.A.. & \\
\hline غُير دال & 1.107 & r.А.. & $T .7 \leq 7$ & العوآمل المقآو \\
\hline غير دال & 1.119 & r.v79 & T.乏Vฯ & الدور الإرشا \\
\hline غير دال & $1 . r \leq r$ & $r . \wedge \leq \tau$ & r.7r. & تدريب القيادان \\
\hline$(\cdots 0)$ & 1.994 & $\varepsilon . .10$ & T.VTr & دور القيادات الريف \\
\hline$(\cdot .0)^{\prime}$ & T. TVY & r.9५人 & $r .01 \leq$ & تحسين وتطوير \\
\hline$(. .00)$ & $r . r \leqslant r$ & r.Avч & r.orr & تقييم البرامج آلتد \\
\hline$(\cdot .+1)$ & $\varepsilon .0 r$. & r.А.. & T.rar & لمهارات العرض والتقديم \\
\hline$(\cdot .0)$ & $r \ldots r$ & $r . \wedge \leq \tau$ & T.OTT & مهارات الاتصال الإد إل \\
\hline$(\cdot .+1)$ & r.110 & $\{. .71$ & r.771 & الأثر التعليمى \\
\hline$(\cdot .1)^{\prime}$ & 0.01 & r.Ат। & r.lor & إمكانية تقديم الخا \\
\hline$(\cdot .1)^{\prime}$ & r.VVq & $r .9 \wedge \varepsilon$ & r.0or & الإرشادي بالمؤسسات والمنظمات \\
\hline غُير دال & 1.9r & r.Аr. & $\mathrm{r} .0 . \mathrm{V}$ & العلاقات التنظيمية بين مكوز \\
\hline غير دال & 1.700 & r.А.. & r.ะqT & الدور الإرشادي لمؤسسات \\
\hline غير دال & $1 . \varepsilon .0$ & $\varepsilon \ldots$ & r.A10 & مشاركة المرأة والثباد \\
\hline$(\cdot . \cdot 1)$ & $r . . \wedge l$ & $\varepsilon . r 94$ & $r .94 \Lambda$ & انتشار الأساليب المزرعية المستحـثة \\
\hline غُير دال & $1.7 Y 7$ & $\varepsilon .1$ Kᄉ & $r .9 r \mu$ & صيانة الموارد الأرضية المزرعية والحفاظ عليها \\
\hline غير دال & $1.9 r \varepsilon$ & E.Ir人 & r.^9r & أسآيب تقليل الفاقد في المحاصيل الزراعية " \\
\hline غير دال & 1.111 & r.Аr. & $r \cdot v \cdot v$ & معوقًات استخدام المعينات | \\
\hline$(\cdot . \cdot)$ & r.^97 & $\varepsilon . .10$ & r.7r. & اكتشاف واختيار القيادرت الريفية " \\
\hline 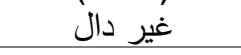 & $\cdot . \wedge 71$ & r.Аr. & $r . v \cdot v$ & اتجاهات الزراع والثباب الريفى نحو متطلبات رفع كفاءة الإنتاج الزراعى \\
\hline
\end{tabular}


الذى يعكس وبوضوح ابتعاد الموضوعات البحثية جزئياً عن تحقيق الأهداف العامة لإستراتيجية التتمية الزراعية المستدامة

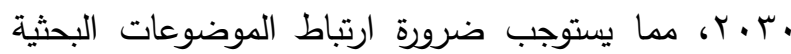
الإرشادية لمعه بحوث الإششاد الزراعي والتمية الريغية

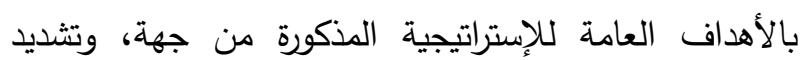
الإشراف من المسئولين عن تتفيذ الخطط البحثية للمعهد ليأتي العمل البحثي متوافقاً مع استراتيجية التنمية الزراعية

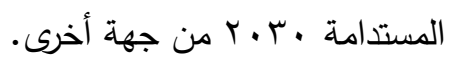

وبترتيب المحاور العامة الستة لإستراتيجية التتمية الزراعية

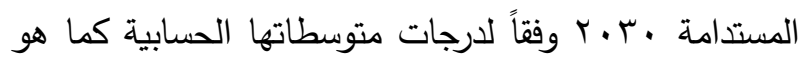
موضح بجدول (Y I)، تبين أن المحور الخاص (بزيادة الإنتاجية الزراعية) بمتوسط (ب9.9) كان أعلى المحاور

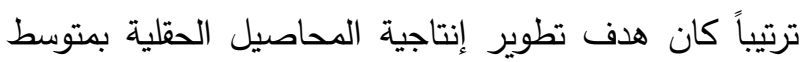

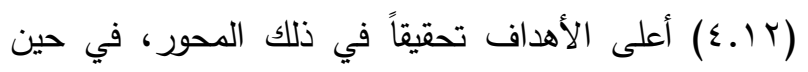
كان أقل الأهداف تحقيقاً له هو هدف تطوير إنتاجية الوحدة

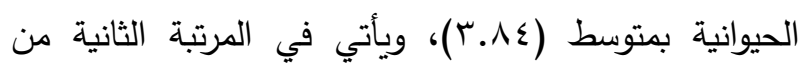
حيث المحاور المحور المتعلق (بتحسين مستوى معيثة السكان الريفيين) بمتوسط (10.ب)، ويليه في المرتبة الثالثة المحور الخاص (بالاستخدام المستدام للموارد الزراعية الطبيعية) بمتوسط (דا.؟؟) كان أعلى الأهداف تحقيقاً لذلك المحور الهدف الخاص "بالتتمية المستدامة لتعظيم إنتاجية الوحدة من الأراضي" بمتوسط (1 (..؟)، بينما كان هدف

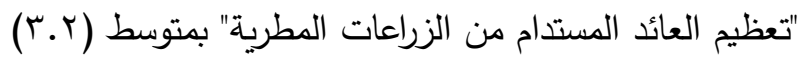
أقل الأهداف تحقيقاً له، وجاء المحور الخاص (بتحقيق معدلات أعلى للأمن الغذائي من السلع الإستراتيجية) بمتوسط (r.or) بالمرتبة الرابعة، حيث كان هدف تحسين جودة وسلامة الغذاء بمتوسط (r.vq) هو أعلى الأهداف تحقيقاً

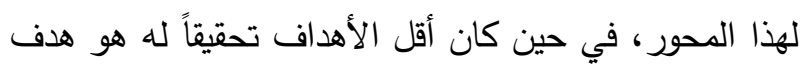

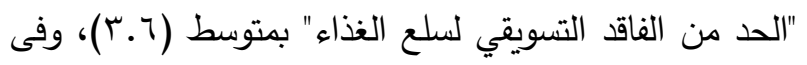
المرتبة الخامسة جاء المحور المتعلق (بتدعيم القدرة التتافسية للمنتجات الزراعية في الأسواق المحلية والدولية) بمتوسط
رابعاً: مستوى توافق الموضوعات البحثية الإرشادية مع الأهداف العامة لإستراتيجية التنمية الزراعية المستدامة $r . r$.

بسؤال المبحوثين عن مدى توافق الموضوعات البحثية الإرشادية المدروسة مع الأهداف العامة لإستراتيجية التتمية

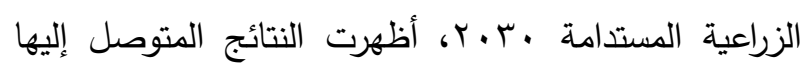
بجدول(1) (1) أن درجات توافق الموضوعات البحثية الإرشادية

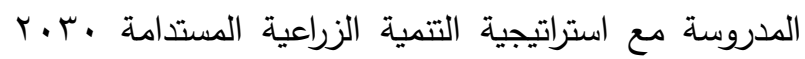
تراوحت من (Yo إلى \& Iا درجة)، وبمتوسط حسابي قدره

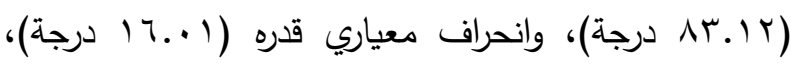

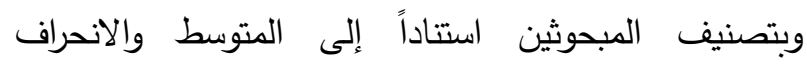

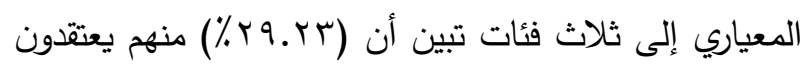

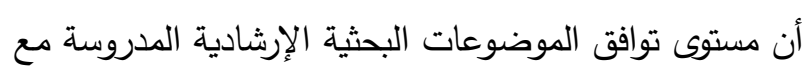

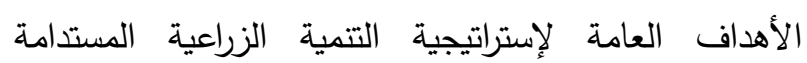

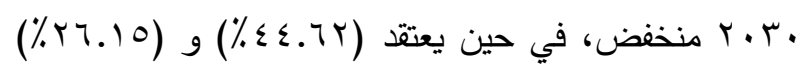
منهم أنه متوسط أو مرتفع على الترتيب. جدول 11. توزيع المبحوثين وفقاً لفئات مستوى توافق الموضوعات البحثية الإشثادية مع الأهداف العامة

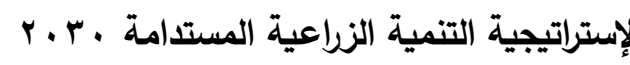

\begin{tabular}{|c|c|c|}
\hline$\%$ & العدد & مستوى التوافت \\
\hline rq.YT & 19 & منخفض (اققل من د د \\
\hline$\varepsilon \varepsilon .7 Y$ & rq & 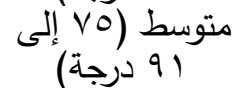 \\
\hline Y..10 & IV & مرتقع (أكثر) دن \\
\hline $1 \ldots$ & 70 & الجملة \\
\hline
\end{tabular}

وتثير النتائج الواردة بجدول (1) (1) أن حوالى ثلاثة أرباع

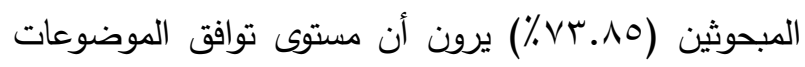
البحثية الإرشادية المدروسة مع الأهداف العامة لإستراتيجية

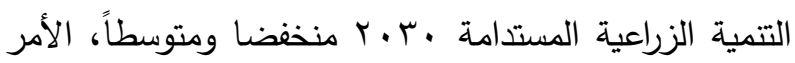




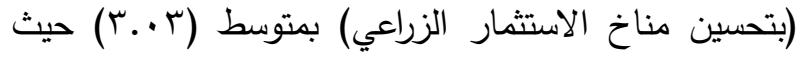
كان هدف "مراجعة السياسات الائتمانية والإقراضية المتعلقة بالزراعة ومشروعاتها" بمتوسط (ب (ب) هو أعلى الأهداف تحقيقاً لهذا المحور، في حين كان هدف "تيسير اجراءات تخصيص الأراضي الجديدة للتعامل مع المستثرين" بمتوسط هيط

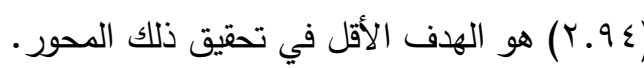

(דץ.ب)، كان هدف "فرص ومبررات تدعيم القدرة التتافسية للمنتجات الزراعية في الأسواق المحلية" بمتوسط (بــ؟) أعلى الأهداف في تحقيق ذلك المحور، بينما كان هدف لاف "فرص ومبررات تدعيم القدرة التتافسية للمنتجات الزراعية في الأسواق الدولية" بمتوسط (q. ب.r) هو أقل الأهداف تحقيقاً

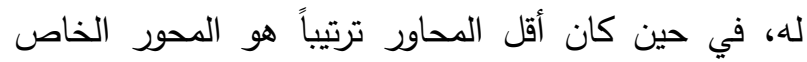

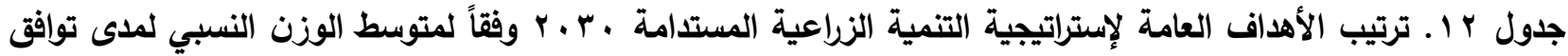
الموضوعات البحثية الإرشادية معها

\begin{tabular}{|c|c|c|c|}
\hline الترتيب & المتوسط* & القيم المعبرة & الأهداف العامة لإستراتيجية التنمية الزراعية المستدامة ، r.r \\
\hline \multirow[t]{7}{*}{1} & $* * r .9 Y$ & & • محور زيادة الإنتاجية الزراعية \\
\hline & ร.) & ห५ & تطوير إنتاجية المحاصيل الحقلية \\
\hline & r.91 & ros & تطوير إنتاجية الوحدة الحيوانية من الألبان \\
\hline & r.9. & ror & تطوير إنتاجية المحاصيل البستانية \\
\hline & r.9. & ror & تطوير إنتاجية الوحدة الحيوانية من الدواجن \\
\hline & r.^० & ro. & تطوير إنتاجية الوحدة الحيوانية من الأسماك \\
\hline & 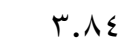 & $r \leq 9$ & تطوير إنتاجية الوحدة الحيوانية من اللحوم \\
\hline r & $* * r . \wedge 0$ & & محور تحسين مستوى معيشة السكان الريفيين وتخفيض معدلات الفقر الرية \\
\hline \multirow[t]{6}{*}{ r } & **r. & & محور الاستخدام المستدام للموارد الزراعية الطبيعية ل \\
\hline & $\varepsilon .+1$ & (4) & التتمية المستدامة لتعظيم إنتاجية الوحدة من الأراضي \\
\hline & r.91 & ros & الزيادة المستدامة لمساحات الأراضي المستصلحة \\
\hline & $r . \vee q$ & $r \leq 7$ & التتمية المستدامة لتعظيم إنتاجية الوحدة من المياه \\
\hline & r.乏r & rtr & صيانة وحماية الأراضي الزراعية \\
\hline & r.r & $r \cdot \Lambda$ & تعظيم العائد المستدام من الزراعات المطرية \\
\hline \multirow[t]{6}{*}{$\varepsilon$} & $* *$ * or & & محور تحقيق معدلات أعلى للأمن الغذائى من السلع الإستراتيجية \\
\hline & r.vq & $r \leq 7$ & تحسين جودة وسلامة الغذاء \\
\hline & r.१人 & rrq & توجيه استخدام الموارد الزراعية المتاحة في توفير سلع الغذاء الإستراتيجية \\
\hline & r.ro & riᄉ & تطوير الأنماط الاستهلاكية لصالح تحسين مستويات التغذية \\
\hline & r.ru & $r \cdot 9$ & توفير وتطوير مقومات الأمان الاجتماعي \\
\hline & r.7 & ז & الحد من الفاقد التسوقي لسلع الغذاء \\
\hline \multirow[t]{3}{*}{0} & **\%.r & & • محور تدعيم القدرة التنافسية للمنتجات الزراعية فى الأسواق المحلية والدولية \\
\hline & $r . \varepsilon r$ & rtr & فرص ومبررات تدعيم القدرة التنافسية للمنتجات الزراعية في الاسواق الدحلية \\
\hline & r.rq & YI $\leq$ & فرص ومبررات تدعيم القدرة التنافسية للمنتجات الزراعية في الاسواق الدولية \\
\hline \multirow[t]{3}{*}{7} & $* * r .+r$ & & • محور تحسين مناخ الاستثمار الزراعي \\
\hline & r.ו & $r \cdot \varepsilon$ & مراجعة السياسات الائتمانية والإقراضية المتعلقة بالزراعة ومشروعاتها \\
\hline & r.9ะ & 191 & تيسير إجراءات تخصيص الأراضي الجديدة للتعامل مع المستثمرين \\
\hline
\end{tabular}

*احتسب المتوسط لكل هدف من أهداف المحاور الستة وفقاً لإجمالي القيم المعبرة عن القيم الفعلية مقسوما على عدد العينة (70)

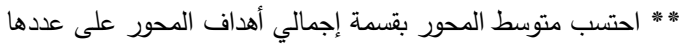




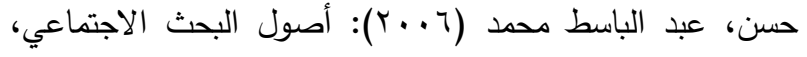
مكتبة وهبة، القاهرة، الطبعة ب إ.

عبيدات، محمد، ومحمد أبو نصار (999 (1): منهجية البحث العلمي القواعد والمراحل والتطبيقات، كلية الاقتصاد والعلوم الإدارية، الجامعة الأردنية، دار وائل.

غانم، إبراهيم البيومي (1 . . ب): مناهج البحث وأصول التحليل في العلوم الاجتماعية، مكتبة الثروق الدولية، القاهرة. محمد، على محمد (9>9 (19): علم الاجتماع والمنهج العلمي، سلسلة علم الاجتماع المعاصر، الطبعة الثانية، دار المعارف الجامعية، الإسكندرية.

معهد بحوث الإرشاد الزراعي والتتمية الريفية، دليل (1 (1): الرؤية، والرسالة، والتظظيم، والأهداف، مركز البحوث الزراعية، وزارة الزراعة واستصلاح الأراضي، جمهورية مصر العربية،

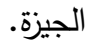

نزار، قنوع، غسان إبراهيم، جمال العص (0. . ب): البحث العلمي في الوطن العربي واقعه ودوره في نقل وتوطين التكنولوجيا، مجلة جامعة تشرين للدراسات والبحوث العلمية - سلسلة العلوم الاقتصادية والقانونية، المجلد (YV)،العدد ؟. ك.

وزارة الزراعة واستصلاح الأراضي (9 ( • ( الاستراتيجية المحدثة للتتمية الزراعية المستدامة في مصر . • ب، القاهرة، ديسمبر . وزان، صالح (9919): تتمية الزراعية العربية الواقع والممكن، مركز دراسات الوحدة العربية، بيروت.

ياقوت، محمد سعد (0. . ب): البحث العلمي العربي، معوقات وتحديات، مجلة الجندول، العدد ع ب، السنة الثالثة.

Alston, J. (2010): The Benefits from Agricultural Research and Development, Innovation, and Productivity Growth, OECD Food, Agriculture and Fisheries Working Papers, No. 31, OECD Publishing. Available on-line at: http://dx.org/10.1787/5km91nfsnkwg-en.

FAO (2017): The future of food and Agricultural: Trends and challenge. Rome. Available on-line at: http://www.fao.org/3/i6583e/i6583e.pdf
ويمكن تفسير تلك النتائج في ضوء استعراض استجابات المبحوثين حول ثلاثة أبعاد مختلفة ترتبط بالأهداف العامة لإستراتيجية التتمية الزراعية المستدامة • ب . : أولاً: بسؤال المبحوثين عن أراءهم حول قابلية الأهداف العامة

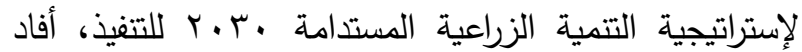

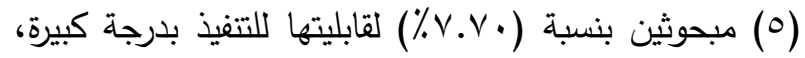

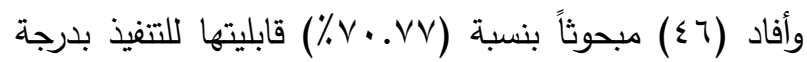

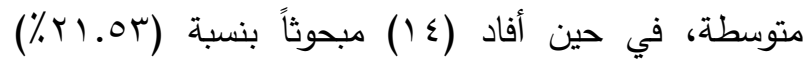
قابليتها للتنفيذ بدرجة ضعيفة. ثانياً: بسؤال المبحوثين عن من أراءهم حول مراعاة الأهداف العامة لإستراتيجية التتمية

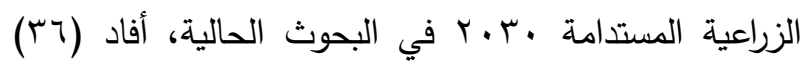
مبحوثاً بنسبة (^ץ.00\%) بمراعاتها بدرجة كبيرة، بينما أفاد

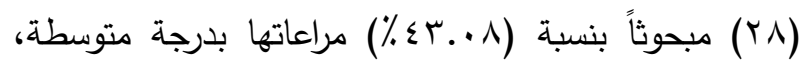

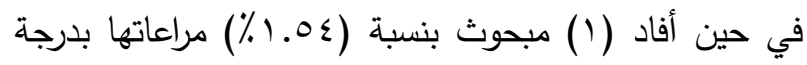
ضعيفة. ثالثاً: بسؤال المبحوثين عن أراءهم حول الاستعداد لمراعاة الأهداف العامة لإستراتيجية التتمية الزراعية المستدامة

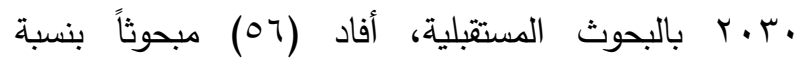

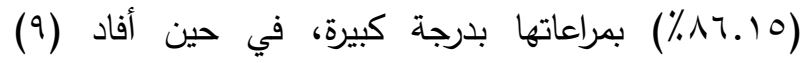
مبحوثين بنسبة (1. ب ا \%) مراعاتها بدرجة متوسطة.

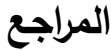

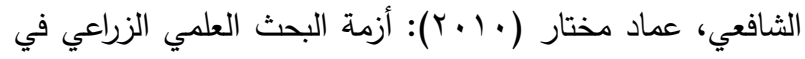

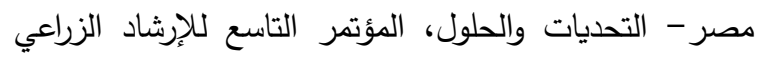
والتتمية الريفية، مركز الخدمات الإرشادية والاستثارية

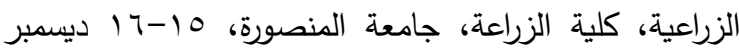
. . . .

الطنوبي، محمد عمر (990 (): الإنتاجية الزراعية بين البحث العلمي والإرشاد الزراعي، منشأة المعارف، الإسكندرية. بدير، سهير (Y1911): البحث العلمي، دار المعارف، الإسكندرية. 


\title{
Analysis of Perceived Importance of Extension Research Topics by Extension Researchers in the Agricultural Extension and Rural Development Research Institute
}

\author{
Magdy Abd El-Wahab Khattab, Mustafa Kamal Hafiz, El-Sawy Mohamed Anwar El-Sawy,
}

\section{Asmaa Mohamed Awadalla, Sherif Rashad Shabaan}

The main objective of this research was to analyze the importance of the extension research topics among the extension researchers at the Agricultural Extension and Rural Development Research Institute AERDRI. This objective was achieved through following subobjectives: (1) Identifying some of the personal and professional characteristics of the researchers of AERDRI. (2) Analyzing the research plans of the (AERDRI) during the period (2012-2017) and classifying them according to the research topics of the (AERDRI). (3) Determining the current and expected importance degrees of the research topics of the research plans of the AERDRI based on the viewpoint of the respondents. (4) Identifying the respondents' opinions related to the extent to which the extension research topics were in line with the research requirements of the 2030 strategy for sustainable agricultural development.

This research was conducted on the members of the research body of the three extension research departments of the AERDRI, who hold the degree of researcher and above: Extension Methods and Audio/Visual Aids Research Department, Extension Programs Research Department, and Extension Organization and Training Research Department. This study was conducted on a systematic random sample of 65 respondents representing $5 r \%$ of the total researchers working in the selected departments. The research data were collected by a pretested interview questionnaire during the period from July to August 2018. The spss.v. 25 was used to analyze the data and the following statistical methods were used: Frequency tables, percentages, arithmetic mean, standard deviation, range, and t-test.

The most important results were as follows:

First: The personal and professional characteristics of the respondents: results showed that most respondents $70.76 \%$ are over 51 years of age. The percent age of Respondents of rural origins $47.70 \%$ was closer to those of urban residents $52.30 \%$. About half of the respondents $49.24 \%$ work in the extension programs department. The research results indicated that $69.23 \%$ of the respondents have reached 18 years or more of their research experience. The number of published papers was high among $80 \%$ of the respondents. More than three quarters of the respondents $75.38 \%$ have a medium and low level of vocational training. The internet, conferences, seminars, workshops, and scientific lectures were the most important sources of agricultural information for the respondents, respectively. $81.54 \%$ of the total respondents have a low and medium level of job satisfaction. The research results indicated that some of the rules of behavior ranked high in terms of presence from the viewpoint of the respondents, namely: considering the personal rights of researchers participating in research $98.47 \%$, objectivity in all stages of research $96.92 \%$, and considering research topics needs and problems of local communities $95.38 \%$. The results showed that $69.23 \%$ of the total respondents believe that the level of influence of the organizations related to their research work was low or medium. Based on the respondents' opinions the most important organizations affecting their research work were: Agricultural Research Center, Central Administration for Agricultural Extension, and the Central Agency for Public Mobilization and Statistics.

Second:Determining the current and expected importance degrees of the research topics of the research plans of the AERDRI: The most important research topics that ranked low according to the current importance were:rural tourism, the possibility of providing paid counseling service, the role of distance education media in extension work, and the level of performance of trainers for presentation and presentation skills. While the most important topics according to the expected importance were: the role of distance education media in extension work, the current and future extension role of cooperative societies, and the extension role of agricultural services institutions.

Third: the level of compatibility of the extension research topics with the general objectives of the 2030 Strategy for Sustainable Agricultural Development: The research results showed that about three quarters of the respondents $(73.85 \%)$ believe that the level of compatibility of the studied research subjects with the general objectives of the 2030 strategy is low or medium

Key Words: Extension Research, Extension researchers, The Agricultural Extension and rural Development and research institute 